\title{
Computer-Aided Approaches to De Novo Design of drug candidates targeting the SARS-CoV-2 Spike protein bound to angiotensin con- verting enzyme 2 (ACE2)
}

\author{
K. G. Kalamatianos* \\ Analytical Chemistry and Toxicology Laboratory, I.Y.A., Athens, Greece, 116-36
}

ABSTRACT: In this study a computer-aided approach to de novo design of chemical entities with drug-like properties against the SARS-CoV-2 Spike protein bound to ACE2 is presented. A structure-based de novo drug design tool LIGANN was used to produce complementary ligand shapes to the SARS-CoV-2 Spike protein $(6 \mathrm{MOJ})$. The obtained ligand structures - potential drug candidates - were optimized and virtually screened. Hit ligands were considered all that showed initial binding energy scores $\leq-9.0 \mathrm{kcal}^{\mathrm{mol}}{ }^{-1}$ for the protein. These compounds were tested for drug-likeness (Lipinski's rule and BOILED Permeation Predictive Model). All satisfying the criteria were re-optimized (geometry \& frequencies) at the HF- $3 \mathrm{c}^{33}$ level of theory and virtually screened against 6M0J. Molecular dynamics (MD) simulations were used to assess the structural stability of selected $6 \mathrm{M} 0 \mathrm{~J} /$ novel compound complexes. Synthetic pathways for selected compounds from commercially available starting materials are proposed.

\section{INTRODUCTION}

Computer-assisted solutions are gaining momentum as a vital method for transforming the process of studying disease mechanisms of action and revolutionizing the understanding of how drugs bind to target molecules while exhibiting high specificity. New potential drug candidates are identified by in silico screening of small molecule libraries targeting specific receptors. Deeplearning algorithms ${ }^{1}$ such as convolutional networks are used for predictions of binding profiles of receptors/target compounds. A different approach is the de novo design of new inhibitors that meet the structural requirements needed to attach specific targets with precision. In this case, only structural data about target macromolecule's binding pocket is required, avoiding the bias of small molecule screening. Deep learning solutions are again at the center of this cutting-edge precision strategy. The benefit is that drugs can be designed easily, with preliminary hit-to-lead results delivered in months, preventing unintended offset interactions. ${ }^{2}$ Recently, potent inhibitors of discoidin domain receptor 1 (DDR1), a kinase target implicated in fibrosis and other diseases were discovered in 21 days. Four compounds were active in biochemical assays, and two were validated in cell-based assays. ${ }^{3}$

In the past four months, several pharmaceutical companies have confirmed hugely promising trials of their Covid-19 vaccines. ${ }^{4}$ This novel coronavirus is the source of a severe pneumonia like illness Covid- $19^{5-6}$ and has led to a worldwide pandemic with more than $123,000,000$ cases and 2,700,000 deaths reported so far. $^{7-12}$ Despite the fact that these vaccines are promising, there is no assurance that they can cure all those who are vaccinated, necessitating the use of other therapies. Antiviral drug discovery is therefore a top priority, despite the fact that it typically takes several years for new drugs to be developed, clinically tested, and approved. Finding already approved drugs with some efficacy against similar types of viruses ${ }^{13}$ and testing their potency against SARS-CoV-2 using computational chemistry methods and virtual molecular docking ${ }^{14-22}$ would be a successful strategy. The most effective of these drugs can then undergo clinical trials and approved. Researchers are attempting to repurpose a wide range of existing drugs, including HIV, HCV, HIV, and influenza medications, for COVID-19. Recently, daclatasvir and sofosbuvir, two antiviral drugs used to treat hepatitis C, have been linked to quicker recovery, decreased hospitalization, and increased survival in people with moderate or serious COVID-19. ${ }^{23}$

A step forward from computer-aided screening of small molecule libraries described above is the de novo design of new compounds that match the structural requirements needed to bind specific binding pockets in target receptors. In previous studies compounds from small molecule libraries including FDA approved antiviral drugs and lopinavir analogues in clinical trials were tested for their inhibitory properties towards the SARSCoV-2 Spike protein ACE2 (6M0J) using a virtual 
screening approach and computational chemistry methods. ${ }^{21,22}$ Among them eight compounds showed excellent results - binding interactions between -9.0 to -11.3 $\mathrm{kcal} . \mathrm{mol}^{-1}$ - for use against the newly emerged strain of coronavirus.

In this study, a computer-aided approach to de novo design of chemical entities with drug-like properties against the SARS-CoV-2 Spike protein bound to ACE2 $(6 \mathrm{MOJ})^{24}$ is presented (Fig. 1). The present work has the following objectives: i) To obtain novel lead compounds that fit with precision the structural criteria required to bind 6M0J (Tables 1-2) using LIGANN a structurebased drug design tool based on generative neuralnetworks ${ }^{25,26,27,28}$ ii) to select all compounds of step (i) that show initial binding affinities $\leq-9 \mathrm{kcal}^{\mathrm{mol}}{ }^{-1}$ with 6M0J after a fast "clean-up" structure optimization iii) To evaluate drug-likeness using the SwissADME tool ${ }^{29}$ and remove compounds of step (ii) that do not obey Lipinski's rule ${ }^{30,31}$ and fail in the Brain Or Intestinal Estimated permeation method ${ }^{32}$ iv) To select as lead compounds all fulfilling the criteria of step (iii) and show final binding affinity $\leq-8 \mathrm{kcal} . \mathrm{mol}^{-1}$ with $6 \mathrm{M} 0 \mathrm{~J}$ after reoptimization at the HF- $3 \mathrm{c}^{33}$ level of theory and virtual screening v) To propose plausible synthetic pathways for selected compounds of step (iv) from commercially available starting materials.

It is known that the virus enters the host cell by binding of the viral spike glycoprotein to the host receptor, angiotensin converting enzyme 2 (ACE2) ${ }^{34}$ therefore (6M0J) seems to be a biologically meaningful receptor.

\section{COMPUTATIONAL METHODS}

$\mathrm{Ab}$ initio molecular orbital calculations were carried out using the ORCA 4.2.1 quantum chemistry program package. ${ }^{35,36,37}$ The most stable optimized geometries and frequency calculations of the compounds studied were obtained from the HF- $3 \mathrm{c}^{33}$ method.

The recent resolved three-dimensional crystal structure of SARS-CoV-2 Spike protein bound to angiotensin converting enzyme 2 (ACE2) (PDB ID: 6M0J) ${ }^{24}$ was retrieved from the Protein Data Bank with a resolution of $2.45 \AA$. Novel compounds were generated by LIGANN $^{27}$ that fit with precision the binding pocket of the protein. The most stable optimized geometries were obtained as described above and were subjected to molecular docking simulation against the SARS-CoV-2 Spike protein (PDB ID: 6M0J) using the AutoDock 4.2/Autodock Vina ${ }^{38}$ and AutoDockFR ${ }^{39}$ softwares. The novel compounds were considered as ligands while the protein as macromolecule. It is well known that in computer aided drug studies, binding affinity and modes of ligand with target protein can be predicted by molecular docking simulation. ${ }^{40,41}$ In this analysis, flexibleligand:rigid-receptor docking was performed and accurate docking conditions were selected. All hetero atoms and water molecules were eliminated before docking. The grid box mapping parameters for AutoDock 4.2/Autodock Vina were chosen as follows: Box dimension $(\AA) \mathrm{x}=61.2777 \quad \mathrm{y}=71.2021 \quad \mathrm{z}=114.7924$ and Center $(\AA) \mathrm{x}=-26.8720 \quad \mathrm{y}=18.4654 \quad \mathrm{z}=-14.0310$ along $\mathrm{x}, \mathrm{y}$ and $\mathrm{z}$ directions respectively.

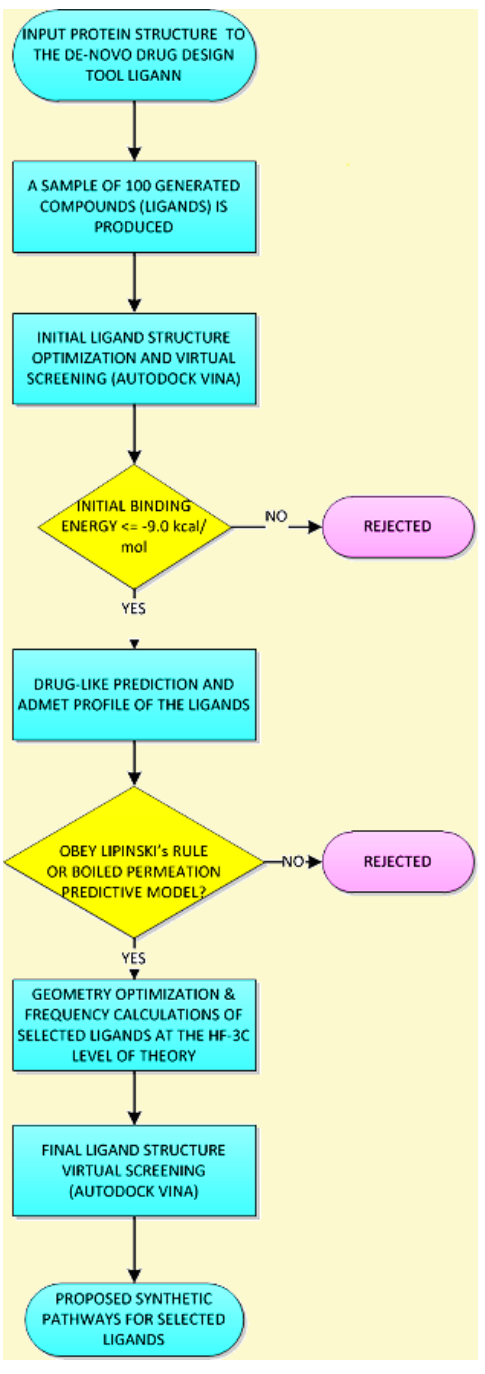

Figure 1. Workflow for identification of potential inhibitors (ligands) against SARS-CoV-2 Spike protein bound to ACE2 (6M0J) (receptor) via de novo design of new compounds that fit, with precision, the structural criteria of the receptor.

\section{RESULTS AND DISCUSSION}

Compounds obtained from the structure-based drug design tool LIGANN and their initial computed binding affinities against 6M0J are shown in Table S1 (Supplementary Material). The binding affinity values $\left(\mathrm{kcal}^{\mathrm{mol}} \mathrm{l}^{-1}\right.$ ) computed by AutoDock 4.2/Autodock Vina ${ }^{38}$ Compounds $\underline{\mathbf{1}}$ - $\underline{\mathbf{1 0}}$ that exhibited initial binding 
affinities $\leq-9 \mathrm{kcal}^{\mathrm{mol}}{ }^{-1}$ with $6 \mathrm{M} 0 \mathrm{~J}$ (Table 1) were tested for drug-likeness and medicinal chemistry friendliness using the SwissADME tool. ${ }^{29}$ Physicochemical descriptors as well as ADME parameters (Absorption, Distribution, Metabolism and Excretion) and pharmacokinetic properties of these small molecules were predicted. To be effective as a drug, a potent molecule must reach its target in the body in sufficient concentration and at a specific bioactive form, and stay there long enough for the expected biologic events to occur. It has been demonstrated that early estimation of ADME parameters in the initial phase reduces drastically the fraction of pharmacokinetics-related failure in the clinical phases. ${ }^{42}$ Two key ADME parameters - the passive gastrointestinal absorption (HIA) and brain access (BBB) for compounds $\underline{\mathbf{1}}-\underline{\mathbf{1 0}}$ were predicted by the SwissADME tool $^{29}$ (Fig. 2). The yellow region is the physicochemical space for highly probable BBB permeation while the white the physicochemical space for highly probable gastrointestinal HIA absorption. Both the yellow and the white regions are not mutually exclusive and the outside grey region stands for molecules with predicted low absorption and limited brain penetration. Two compounds $\underline{\mathbf{2}}$ and $\underline{\mathbf{9}}$ (Fig. 2) were predicted as not absorbed and not brain penetrant and they were excluded from further study. Compounds $\underline{\mathbf{3}}, \underline{\mathbf{4}} \underline{\mathbf{5}}, \underline{\mathbf{8}}$ and $\underline{\mathbf{1 0}}$ (Fig. 2) were predicted as passively crossing the $\mathrm{BBB}$, but pumped-out from the brain (PGP+, blue dot) while $\underline{\mathbf{1}}, \underline{\mathbf{6}}$

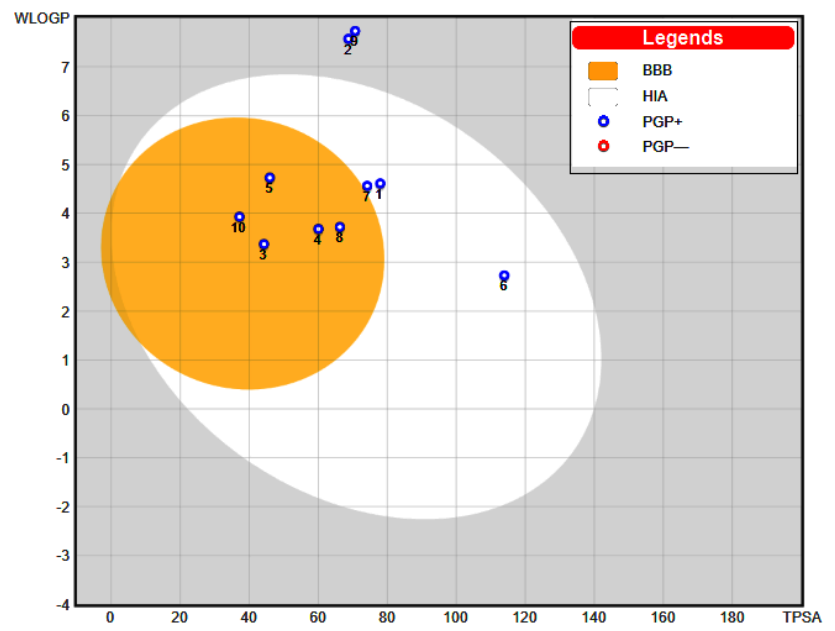

Figure 2. Evaluation of passive gastrointestinal absorption (HIA) and brain penetration (BBB) in function of the position of compounds $\underline{1}-\underline{10}$ in the WLOGP-versus-TPSA referential. Molecules in the white region $(\underline{1}, \underline{6}$ and $\underline{7})$ have the highest probability of being absorbed by the gastrointestinal tract, while those in the yellow region $(3, \underline{4}, \underline{5}, \underline{8}, \underline{10})$ have the highest probability to permeate to the brain. Compounds in the grey region ( $\underline{2}$ and $\underline{9}$ ) are predicted as not absorbed and not brain penetrant.

and $\underline{7}$ well-absorbed but not accessing the brain and PGP+ (blue dot). Four ligands $\underline{\mathbf{3}}, \underline{\mathbf{4}}, \underline{\mathbf{5}}$ and $\underline{\mathbf{7}}$ were found also to obey Lipinski's rule ${ }^{30,31}$ of five showing zero violations while the rest show a maximum of two violations (Table 1 and Table S2 in Supplementary Material).

Compounds of Table 1 - except $\underline{\mathbf{2}}$ and $\underline{\mathbf{9}}$ that failed in the above mentioned drug-likeness tests - were reoptimized at the HF- $3 \mathrm{c}^{33}$ level of theory and their HOMO and LUMO energies, HOMO-LUMO energy gap values and nucleophilicity indices ${ }^{43} \mathrm{~N}$ were calculated from these values as shown in previous papers. ${ }^{21,22}$ The binding affinities - averages of ten independent trials - of these compounds against 6M0J were computed by AutoDock 4.2/Autodock Vina and AutoDockFR (Table 2).

The results obtained show that best binding energies $\left(<-9.0 \mathrm{kcal} . \mathrm{mol}^{-1}\right)$ are observed in most cases for drugs that exhibit low nucleophilicity indices $\mathrm{N}$ (more electrophilic compounds) (Table 2, AD Vina). The nucleophilicity index $\mathrm{N}$ encompasses the tendency of a nucleophile to donate an extra amount of electron density. A plot of binding affinities vs. compound nucleophilicity indeces $\mathrm{N}$ (excluding outliers, compounds $\underline{\mathbf{7}}$ and $\underline{\mathbf{1 0}}$ ) showed excellent correlation $\left(\mathrm{R}^{2}=0.979\right)($ Fig. 3$)$.

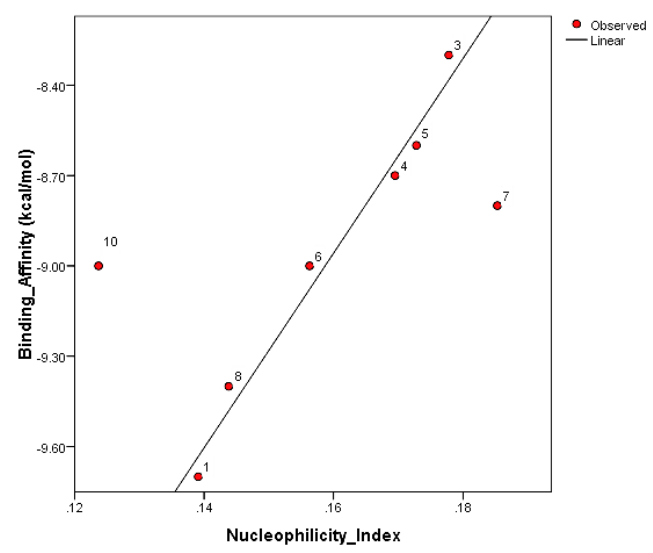

Figure 3. Binding affinities of compounds in Table 2 (except 7 and 10) vs. their nucleophilicity indeces $(R 2=0.979)$.

The highest virtual screening scores to $6 \mathrm{M} 0 \mathrm{~J}$ among the inhibitors $\underline{\mathbf{1}} \underline{\mathbf{1 0}}$ were observed for $\underline{\mathbf{1}}, \underline{\mathbf{8}}, \underline{\mathbf{6}}$ and $\underline{\mathbf{1 0}}(-9.7$, $-9.4,-9.0,-9.0 \mathrm{kcal}^{\mathrm{mol}} \mathrm{m}^{-1}$ respectively Fig. 3 and Table 2 ). The higher binding affinity observed for these compounds against the receptor can be attributed mainly to non-covalent interactions. The formed ligand (compound in Table 2) - protein/receptor (6M0J) complexes reveal that Pi-alkyl, Pi-Pi T-shaped, Pi-Pi stacked, conventional hydrogen bonding and halogen bonds are able to increase the binding affinity and explain the differences in binding energies (Table I, Appendix A). It is well known that particularly hydrogen bonds $<2.3 \AA$ are able to increase the binding affinity considerably and that halogen bonds have almost similar importance as hydrogen bonds in biological and chemical systems. ${ }^{44,45}$ 
Considerable hydrogen bonding was observed between the above compounds and the protein including hydrogen bonds $<2.3 \AA$ (Fig.4- Fig.7). Docking interactions of 1 (Tables A1, 1 and 2) with 6M0J are shown in Fig. 4. Seven Pi-Alkyl with PHE40, TRP349, HIS378, PHE390, HIS401 and three alkyl interactions with ALA348, ARG393, LEU391 were observed. Four hydrogen bon-

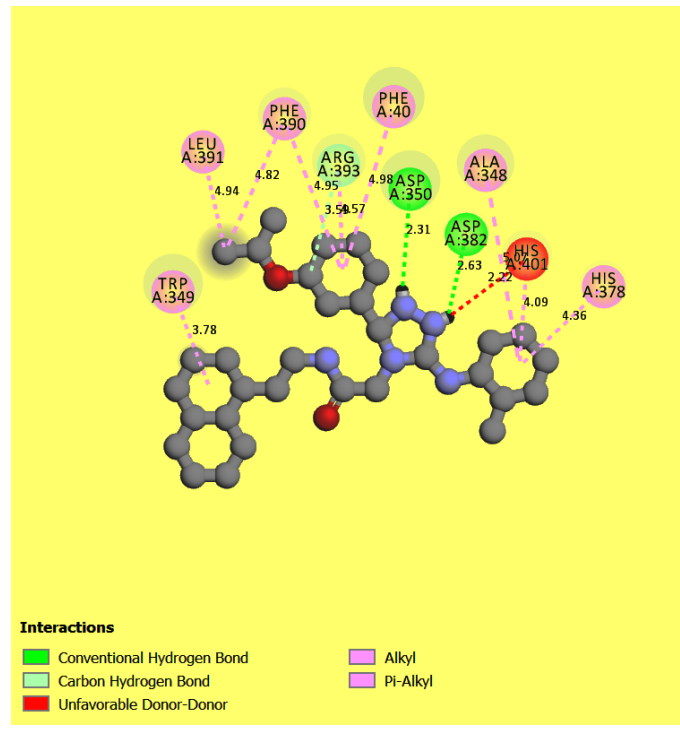

Figure 4. Docking interactions of compound 1 (Tables 1 \& 2) with $6 \mathrm{MOJ}$ (expanded version in Appendix A).

formed with ASP382, ASP350, ARG393, GLU208 with the latter $<2.3 \AA$ A. Compound $\underline{\mathbf{8}}$ formed three Pi-Pi T-

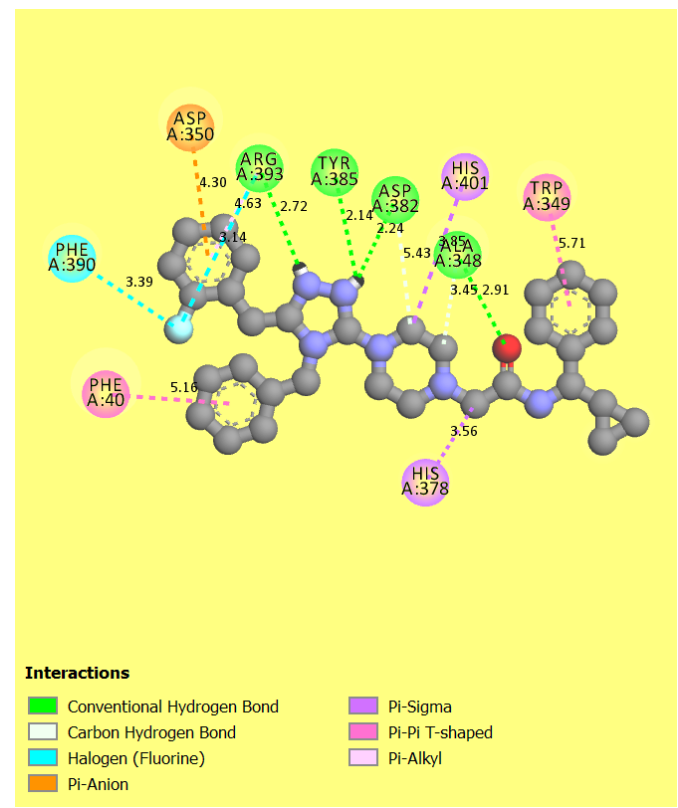

Figure 5. Docking interactions of compound 8 (Tables 1 \& 2) with $6 \mathrm{MOJ}$ (expanded version in Appendix A).

Shaped bonds with the residues PHE40 and TRP349, two Pi-Sigma with HIS401 and HIS378 and a Pi-Alkyl with ARG393 (Fig. 5). Seven hydrogen bonds were formed with the residues ARG393, ASP382 $(<2.3 \AA)$, TYR385 $(<2.3 \AA)$, ALA348. Two halogen bonds interactions were evident with PHE390 and ARG393 (Fig. 5). The docked assembly of $\underline{\mathbf{1 0}}$ with $6 \mathrm{M} 0 \mathrm{~J}$ consisted of two Pi-Alkyl interactions with ILE291 and LEU37, one Pi-Pi T-shaped with PHE438 and three hydrogen bond interactions with SER409 and ASN290 (Fig. 6). It should be
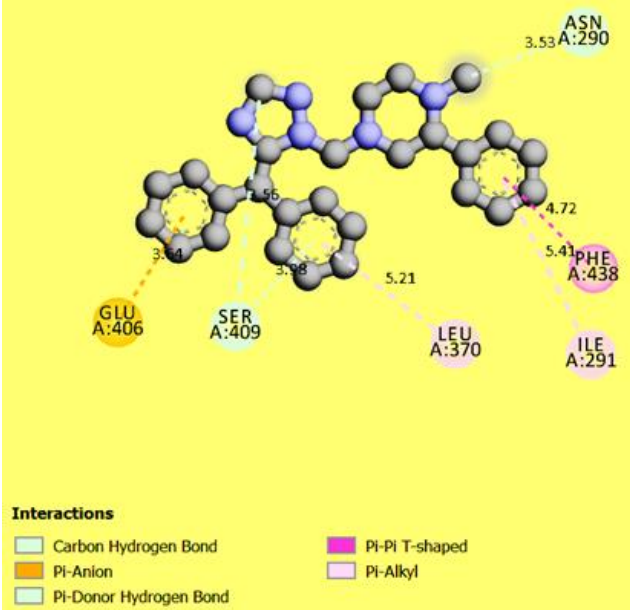

Figure 6. Docking interactions of compound 10 (Tables $1 \& 2$ ) with 6MOJ (expanded version in Appendix A).

mentioned that the relatively high affinity of $\underline{\mathbf{1 0}}$ for the protein compared to $\underline{\mathbf{7}}, \underline{\mathbf{4}}, \underline{\mathbf{5}}$ and $\underline{\mathbf{3}}$ can be partly attributed
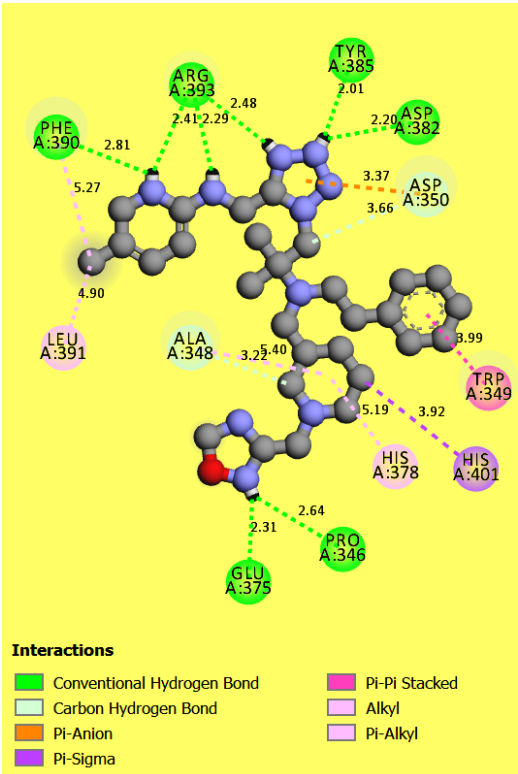

Figure 7. Docking interactions of compound $\underline{6}$ (Tables $1 \& 2$ ) with $6 \mathrm{MOJ}$ (expanded version in Appendix A).

to its electrophilicity (lowest nucleophilicity index in Table 2). Compound $\underline{6}$ formed 10 hydrogen bonds with 
TABLE 1: List of compounds (ligands) 1-16 docked against the SARS-CoV-2 spike protein 6M0J.

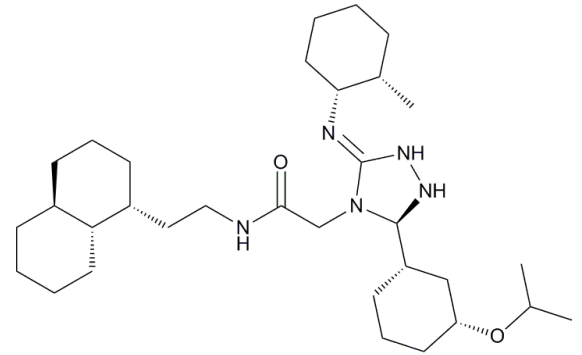

1

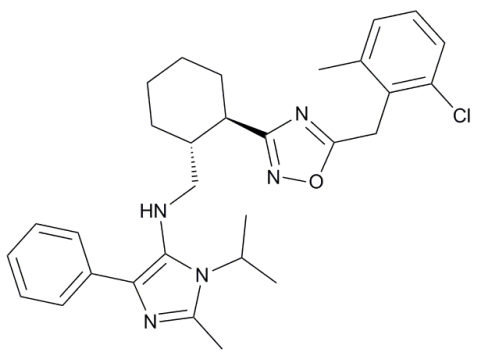

$\underline{2}$

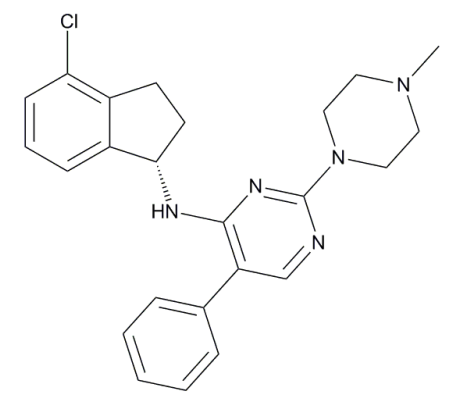

$\underline{3}$

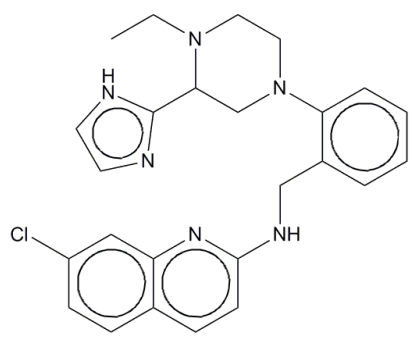

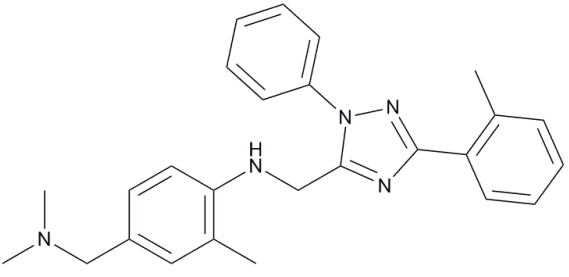

$\underline{5}$

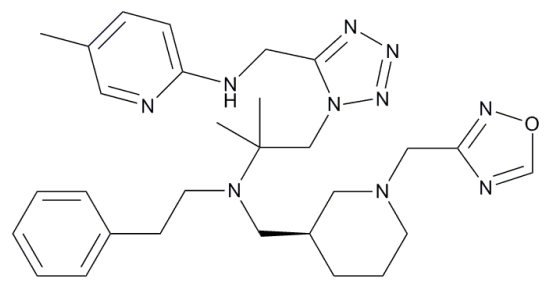

$\underline{6}$

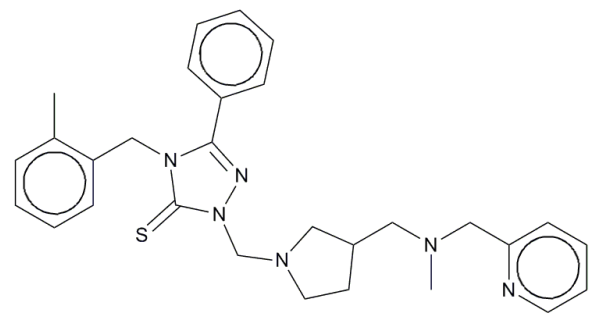

I

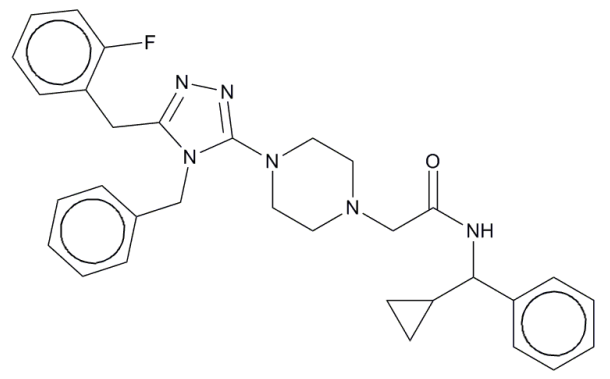

$\underline{8}$ 
TABLE 1 (continued): List of compounds 1-16 (ligands) docked against the SARS-CoV-2 spike protein 6M0J.

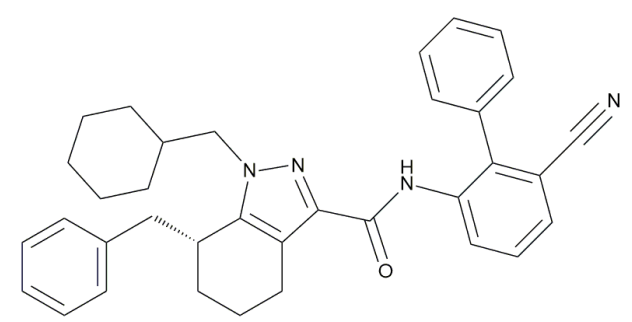

$\underline{9}$

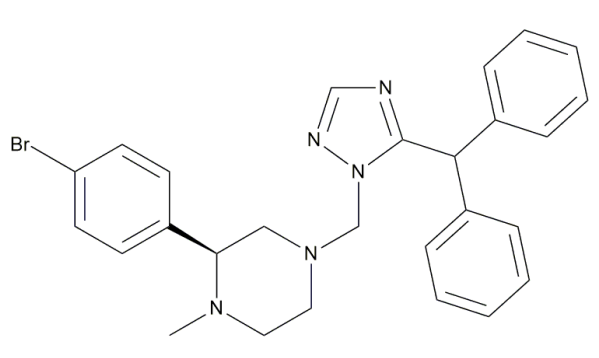

10

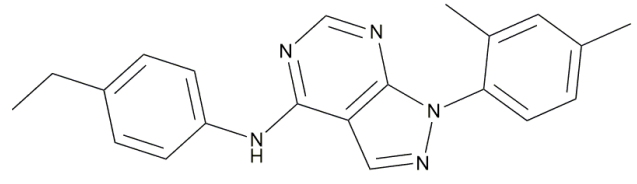

11

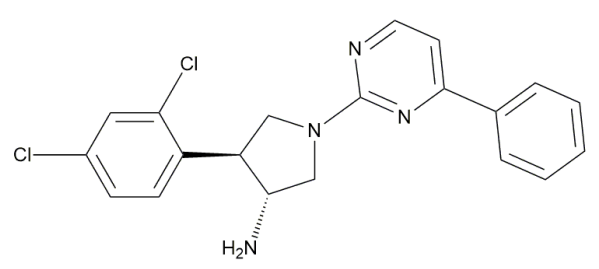

12

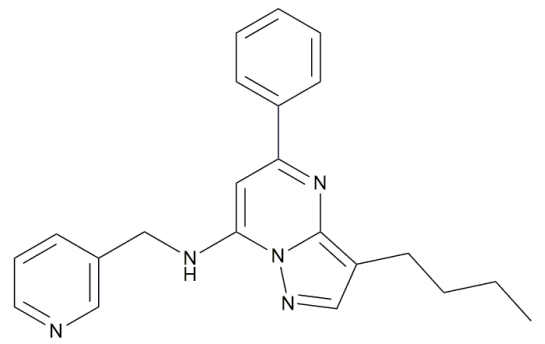

$\underline{13}$

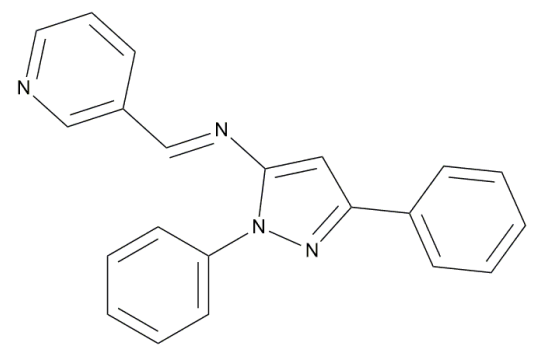

14

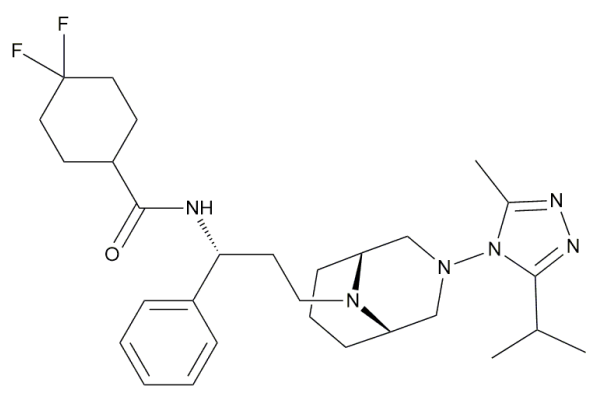

15

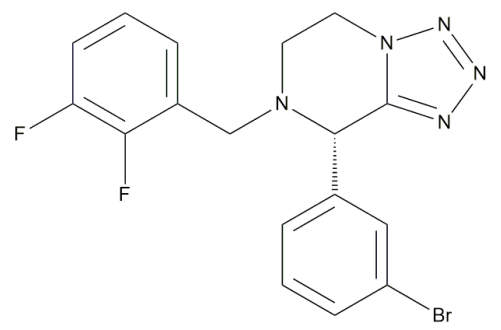

16 
TABLE 2: Global reactivity descriptor, physicochemical, pharmacokinetic and binding affinity (kcal.mol-1) data of the new drug candidates $\underline{1}$ to $\underline{10}$ (except $\underline{2}$ and $\underline{9}$ ) of Table 1 against $6 \mathrm{MOJ}$.

\section{\# Compound \# HOMO - LUMO}

in Table 1
Energy Gap (a.u)

\section{Molecular}

Formula

\section{Molecular}

Weight (amu)
TPSA

$\left(\AA^{2}\right)$

$\begin{array}{ll}\text { Binding } & \text { Binding } \\ \text { Affinity } & \text { Affinity }\end{array}$

(AD Vina) (AutoDockFR )

1

8

0.4690

0.4816

$\mathrm{C}_{27} \mathrm{H}_{28} \mathrm{BrN}_{5}$

$\mathrm{C}_{29} \mathrm{H}_{40} \mathrm{~N}_{10} \mathrm{O}$

544.69

498.69

$\mathrm{C}_{29} \mathrm{H}_{34} \mathrm{~N} 6 \mathrm{~S}$

$\mathrm{C}_{25} \mathrm{H}_{27} \mathrm{ClN}_{6}$

446.98

$\mathrm{C}_{26} \mathrm{H}_{29} \mathrm{~N}_{5}$

411.54

$\mathrm{C}_{24} \mathrm{H}_{26} \mathrm{ClN}_{5}$

419.95

$\mathrm{C}_{24} \mathrm{H}_{26} \mathrm{ClN}$

0.4250

0.4114

0.4068

250


TABLE 3: Binding affinity data of known bioactive inhibitors $\underline{11}$ to $\underline{16}$ against $6 \mathrm{M} 0 \mathrm{~J}$, that show Tanimoto similarity $>0.8$ with the corresponding new drug candidates of Table 2

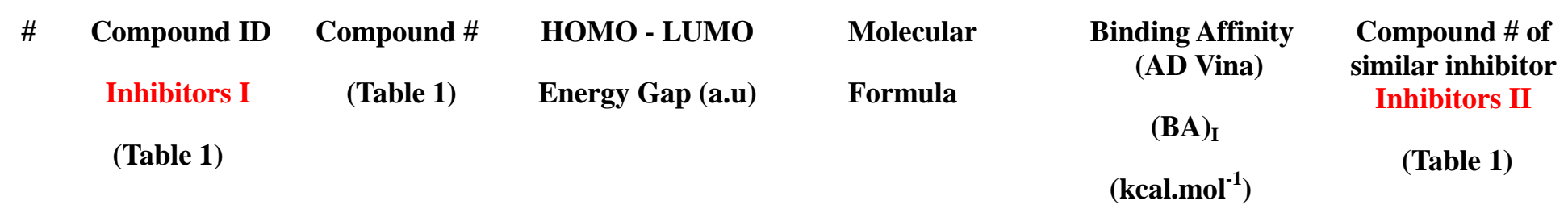

$\begin{array}{cc}\begin{array}{c}\text { Binding Affinity } \\ (\text { AD Vina })\end{array} & \begin{array}{c}\text { Binding } \\ \text { Affinity } \\ \text { Difference }\end{array} \\ (\text { BA })_{\text {II }} & (\text { BA })_{\text {II }}-(\text { BA })_{\text {I }} \\ \left(\text { kcal.mol }^{-1}\right) & \left(\text { kcal.mol }^{-1}\right)\end{array}$

$1 \quad$ CID 949757

2 CID 11998979

3 CID 44444338

$4 \quad$ CID 693921

$5 \quad$ CID 145959679

$6 \quad$ CID 118169484
11

12

13

14

15

16
0.4068

0.4200

0.3884

0.3856

0.5124

0.4812

\section{$\mathrm{C}_{21} \mathrm{H}_{21} \mathrm{~N}_{5}$}

$\mathrm{C}_{20} \mathrm{H}_{18} \mathrm{Cl}_{2} \mathrm{~N}_{4}$

$\mathrm{C}_{22} \mathrm{H}_{23} \mathrm{~N}_{5}$

$\mathrm{C}_{21} \mathrm{H}_{16} \mathrm{~N}_{4}$

$\mathrm{C}_{29} \mathrm{H}_{42} \mathrm{~F}_{2} \mathrm{~N}_{6} \mathrm{O}$

$\mathrm{C}_{17} \mathrm{H}_{14} \mathrm{BrF}_{2} \mathrm{~N}_{5}$
$-9.3$

$-9.3$

$-9.0$

$-8.6$

$-8.7$
5

3

6

7

8

10
$-8.6$
0.7

1.0

0

$-0.2$

$-0.1$

$-0.3$ 
a)

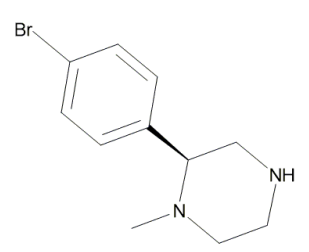

17

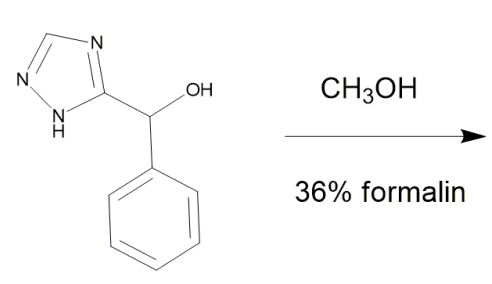

18

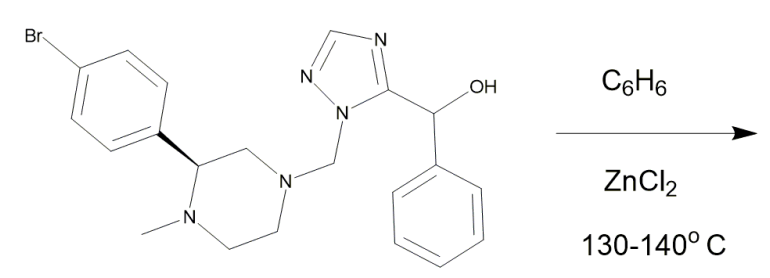

$\underline{19}$

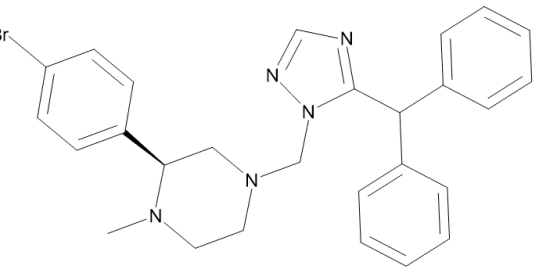

10

b)

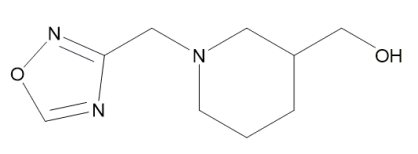

$\underline{20}$

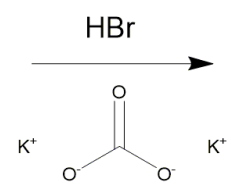

$0^{-}$

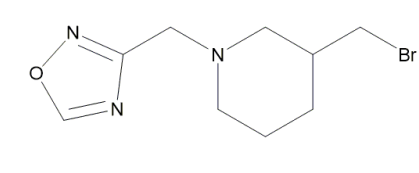

$\underline{21}$

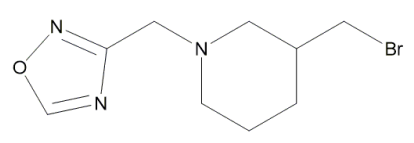

$\underline{21}$

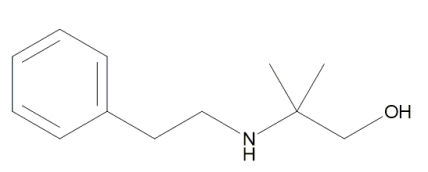

$\underline{22}$

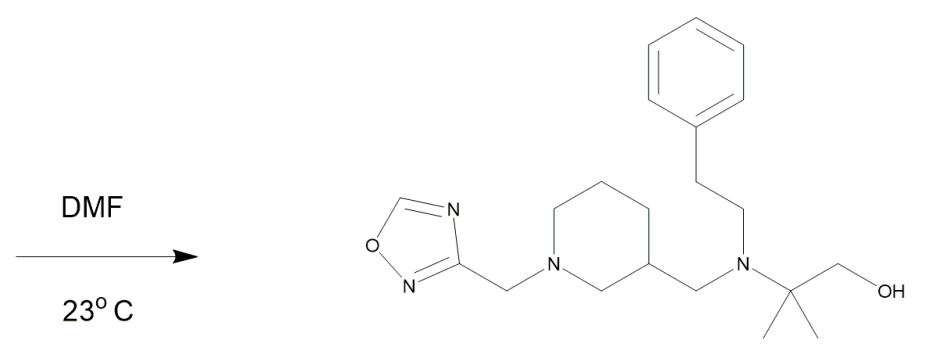

$\underline{23}$

Scheme 1: Plausible reaction pathways to the target compounds $\underline{10}, \underline{6}$ and $\underline{4}$ 
b)

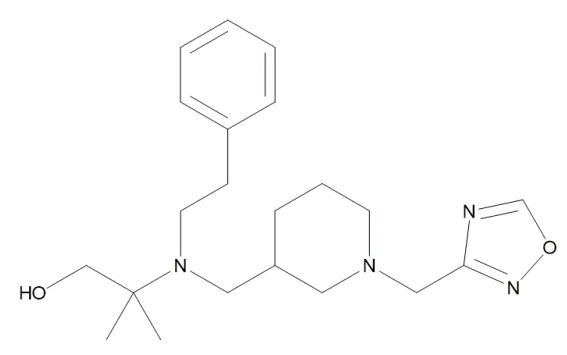

$\underline{23}$

c)

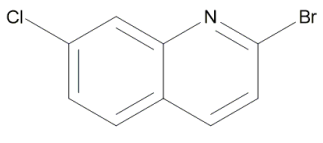

$\underline{25}$

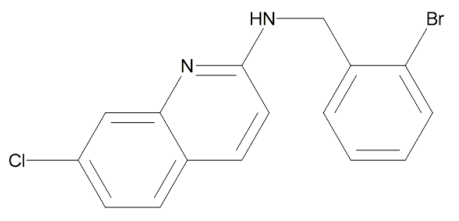

$\underline{28}$

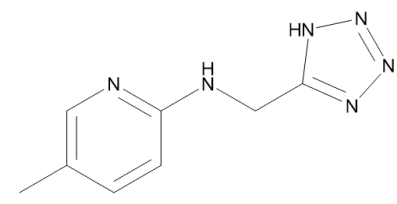

$\underline{24}$

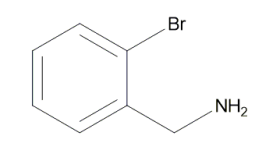

$\underline{26}$

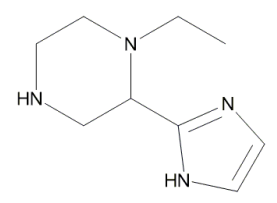

$\underline{29}$

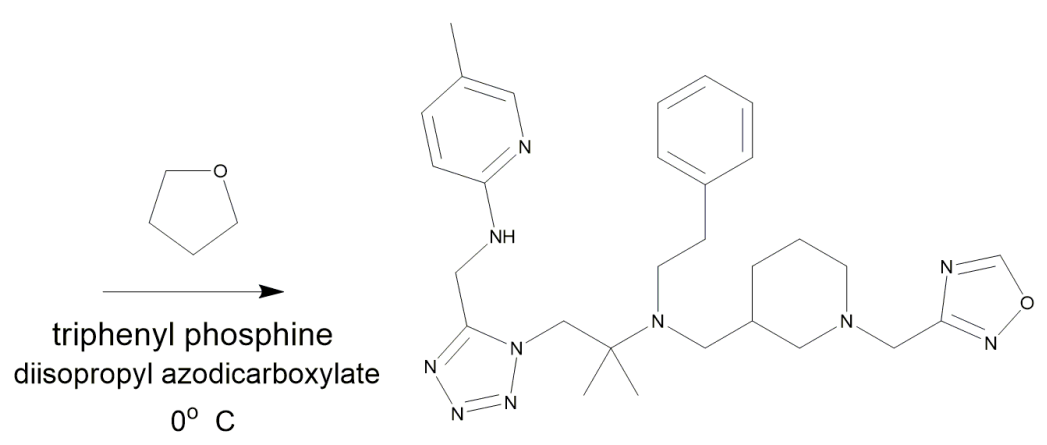

$\underline{6}$

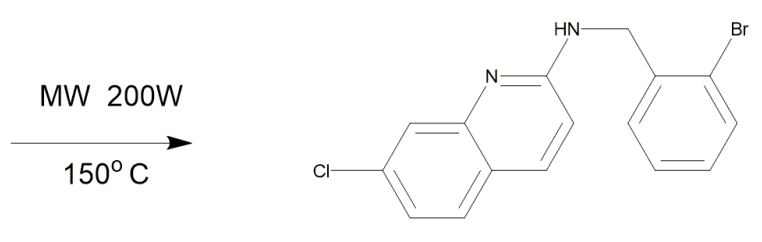

$\underline{27}$

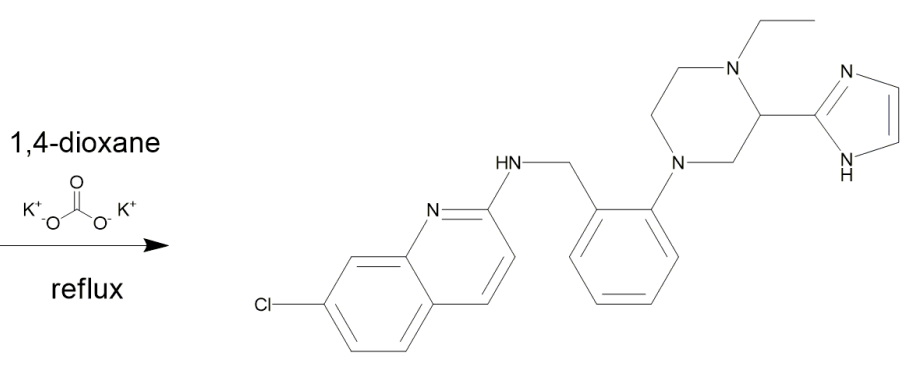

4 
the residues ARG393 $(<2.3 \AA)$, ASP382 $(<2.3 \AA)$, TYR385 (<2.3 $\AA), \quad$ PHE390, PRO346, GLU375, ASP350 and ALA348. Two Pi-Pi stacked interactions were observed with TRP349, two Pi-Alkyl with HIS378 and PHE390 and two Alkyl interactions with LEU391 and ALA348 (Fig. 7).

The generated small molecules $\underline{\mathbf{1}} \mathbf{- 1 0}$ in Table 1 (except $\underline{\mathbf{2}}$ and 9 ) were further examined regarding their similarity to known antiviral drugs. Similarity was measured using the Tanimoto equation ${ }^{46,47}$ and the PubChem dictionary-based binary fingerprint. This fingerprint consists of series of chemical substructure keys that denote the presence or absence of a particular substructure in a molecule. This similarity search ${ }^{48}$ assumes that all compounds that are similar have similar biological activity. Although this hypothesis is not always valid, ${ }^{49}$ quite often such similar compound sets are considerably enriched with bioactives. ${ }^{50}$ Six molecules $(\underline{\mathbf{3}}, \underline{\mathbf{5}}-\underline{\mathbf{8}}$ and 10) were found to have Tanimoto similarity $>0.8$ with antiviral drugs in clinical trials (11- 16, Table 3) while three of them - $\underline{\mathbf{7}}, \underline{\mathbf{8}}$ and $\underline{\mathbf{1 0}}$ - show in addition higher virtual screening score from the latter (Table 3 ). Similar compounds with Tanimoto similarity $>0.8$ could not be found for $\underline{1}$ and $\underline{4}$.

However, the major challenge faced in de novo design is the synthetic feasibility of the generated inhibitors. In an attempt to address this problem plausible synthetic pathways are proposed for compounds $\underline{\mathbf{4}} \underline{\mathbf{6}}$ and $\underline{\mathbf{1 0}}$ that show good pharmakokinetic properties and higher virtual screening scores than Tanimoto similar compounds. Compound $\underline{\mathbf{1 0}}$ can be synthesized in a two-step process ${ }^{51}$ from the commercially available starting materials 2-(4bromophenyl)-1-methylpiperazine $\underline{\mathbf{1 7}}$ and phenyl( $1 \mathrm{H}$ 1,2,4-triazol-5-yl)methanol $\underline{\mathbf{1 8}}$ (Scheme 1a). Compound $\underline{6}$ can be prepared by a three-step reaction process ${ }^{52,53}$ from the readily available (1-((1,2,4-oxadiazol-3yl)methyl)piperidin-3-yl)methanol $\underline{\mathbf{2 0}}$, 2-methyl-2(phenethylamino)propan-1-ol $\underline{\mathbf{2 2}}$ and $\mathrm{N}-((1 \mathrm{H}-$ tetrazol-5yl)methyl)-5-methylpyridin-2-amine $\underline{\mathbf{2 4}}$ as shown in Scheme $1 \mathrm{~b}$. The two bromo $\mathrm{N}$-arylation reactions depicted in Scheme 1c can be used for the preparation of inhibitor $\underline{\mathbf{4}}$ from 2-bromo-7-chloroquinoline $\underline{\mathbf{2 5}}$, (2bromophenyl)methanamine $\underline{\mathbf{2 6}}$ and 1-ethyl-2- $(1 \mathrm{H}-$ imidazol-2-yl)piperazine $\underline{\mathbf{2 9}}$.

An additional but equally important challenge faced in the de novo design is the stability of the formed protein-novel compound complexes. The docking interactions diagrams (Figs. 4-7) reveal that Pi-Alkyl, Pi-Pi stacked interactions and hydrogen and halogen bonds are able to increase the binding affinity and explain differences in binding energies. Molecular dynamics (MD) simulations were further used to assess structural stability of the $6 \mathrm{M} 0 \mathrm{~J}$ and $\underline{\mathbf{6}}, \underline{\mathbf{7}}$ and $\underline{\mathbf{8}}$ complexes respectively.
These structures were subjected to fully solvated atomistic MD simulations using VMD ${ }^{54,55}$ and NAMD.$^{56} \mathrm{MD}$ simulations were conducted at $310 \mathrm{~K}$ for $40 \mathrm{~ns}$. Structural fluctuations of protein and the ligands are indicated by variation in the root mean square variation (RMSD). The RMSD of the free protein remained stable after $8 \mathrm{~ns}$ at $2 \AA$ (Fig. 8). The RMSD of the $6 \mathrm{M} 0 \mathrm{~J}$ and $\underline{\mathbf{6}}$ complex initially increased for about $8 \mathrm{~ns}$ and then fluctuated between 2.0 and $2.25 \AA$ while that of $\underline{\mathbf{Z}}$ initially increased for about $14 \mathrm{~ns}$ and then slightly fluctuated around $2.1 \AA$. As shown in Fig. 8 the RMSD of the 6M0J and $\underline{\mathbf{8}}$ complex was balanced after $16 \mathrm{~ns}$ and then fluctuated around 2.0 A. MD analysis revealed that the studied complexes have shown structural stability during the runs.

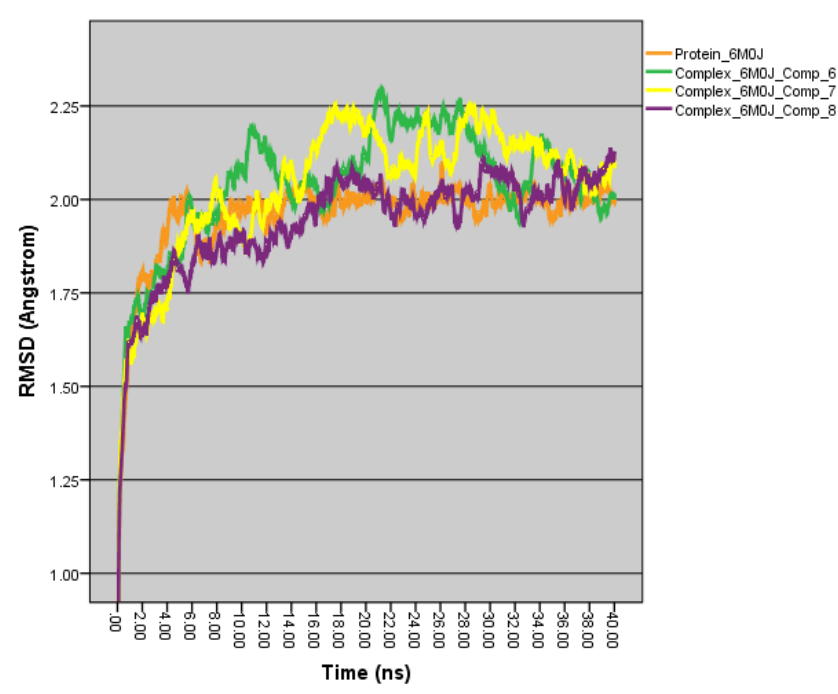

Figure 8. MD simulation RMSD plots ( $40 \mathrm{~ns}, 310 \mathrm{~K}$ ) of free $6 \mathrm{MOJ}$ and of complexes of $6 \mathrm{MOJ}$ with compounds $\underline{6}-\underline{8}$ (Tables 1 \& 2 ).

As shown in Fig. 8 the RMSD of the $6 \mathrm{M} 0 \mathrm{~J}$ and $\underline{\mathbf{8}}$ complex was balanced after $16 \mathrm{~ns}$ and then fluctuated around $2.0 \AA$. The MD analysis revealed that the studied complexes have shown structural stability during the runs.

\section{CONCLUSIONS}

Computer-aided approaches to de novo drug design play an increasingly important role in the development of novel drugs. This approach is considered a step forward from in silico screening of small molecule libraries since the new candidate compounds fit with precision the structural criteria required to bind specific targets. The advantage is that novel drugs can be designed quickly saving the limited resources, avoiding unwanted offset interactions, with results delivered in months. In this study a computer-aided approach to de novo design 
of chemical entities with drug-like properties against the SARS-CoV-2 Spike protein bound to ACE2 is presented. A structure-based de novo drug design tool LIGANN was used to produce complementary ligand shapes to the SARS-CoV-2 Spike protein (6M0J). The obtained ligand structures - potential drug candidates - were optimized and virtually screened. Hit ligands were considered all that showed initial binding energy scores $\leq-9.0$ $\mathrm{kcal} . \mathrm{mol}^{-1}$ for the protein. These compounds $\underline{\mathbf{1}} \underline{\mathbf{1 0}}$ were in silico tested for drug-likeness and two of them excluded from further study because they were predicted as not absorbed and not brain penetrant. All satisfying the criteria were re-optimized (geometry $\&$ frequencies) at the HF- $3 \mathrm{c}^{33}$ level of theory and virtually screened against $6 \mathrm{M} 0 \mathrm{~J}$. The binding affinities - averages of ten independent trials - of these compounds against $6 \mathrm{M} 0 \mathrm{~J}$ were computed by AutoDock 4.2 / Autodock Vina and AutoDockFR. The results obtained show that best binding energies $\left(<-9.0 \mathrm{kcal} . \mathrm{mol}^{-1}\right)$ are observed in most cases for drugs that exhibit among others low nucleophilicity indices $\mathrm{N}$ (more electrophilic compounds). The docking interactions diagrams (Figs. 4-7) revealed that Pi-Alkyl, Pi-Pi stacked interactions and hydrogen and halogen bonds were able to increase the binding affinity and explain differences in binding energies. Molecular dynamics (MD) simulations were further used to assess the structural stability of the $6 \mathrm{MOJ}$ and $\underline{\mathbf{6}}, \underline{\mathbf{7}}$ and $\underline{\mathbf{8}} \mathrm{com}-$ plexes respectively. The MD analysis revealed that the studied complexes have shown structural stability during the runs. Furthermore, the major challenge faced in de novo design the synthetic feasibility of the generated inhibitors was addressed by proposing plausible two or

\section{DISCLOSURE STATEMENT}

No potential conflict of interest is reported by the author.

\section{ORCID}

\section{K. G. Kalamatianos (B) 0000-0002-0276-6531}

\section{CONTACT}

K. G. Kalamatianos kgkalamatianos@gmail.com Analytical Chemistry \& Toxicology Laboratory, I.Y.A., Athens, Greece 116-36 three-step synthetic pathways for compounds $\underline{\mathbf{4}}, \underline{\mathbf{6}}$ and 10. The current results suggest that computer aided drug design approaches relying on receptor structure-based methodologies could be used with success to predict new more potent antiviral agents against the SARSCoV-2.

\section{REFERENCES}

(1) $\quad$ AI for Advanced R\&D and Drug Discovery Q2_2019 - AI in Drug Discovery.

(2) Deloitte. Intelligent Drug Discovery About the Deloitte Centre for Health Solutions. 2020.

(3) Zhavoronkov, A.; Ivanenkov, Y. A.; Aliper, A.; Veselov, M. S.; Aladinskiy, V. A.; Aladinskaya, A. V; Terentiev, V. A.; Polykovskiy, D. A.; Kuznetsov, M. D.; Asadulaev, A.; Volkov, Y.; Zholus, A.; Shayakhmetov, R. R.; Zhebrak, A.; Minaeva, L. I.; Zagribelnyy, B. A.; Lee, L. H.; Soll, R.; Madge, D.; Xing, L.; Guo, T.; Aspuru-Guzik, A. Deep Learning Enables Rapid Identification of Potent DDR1 Kinase Inhibitors. Nat. Biotechnol. 2019, 37 (9), 1038-1040. https://doi.org/10.1038/s41587-019-0224-x.

(4) Gallagher, J. Covid Vaccine Update: When Will Others Be Ready? BBC News. 2020.

(5) Gorbalenya, A. E.; Baker, S. C.; Baric, R. S.; de Groot, R. J.; Drosten, C.; Gulyaeva, A. A.; Haagmans, B. L.; Lauber, C.; Leontovich, A. M.; Neuman, B. W.; Penzar, D.; Perlman, S.; Poon, L. L. M.; Samborskiy, D. V; Sidorov, I. A.; Sola, I.; Ziebuhr, J.; Viruses, C. S. G. of the I. C. on T. of. The Species Severe Acute Respiratory Syndrome-Related Coronavirus: Classifying 2019-NCoV and Naming It SARS-CoV-2. Nat. Microbiol. $\quad 2020, \quad 5 \quad$ (4), 536-544. https://doi.org/10.1038/s41564-020-0695-z.

(6) Kupferschmidt, K.; Cohen, J. Will Novel Virus Go Pandemic or Be Contained? Science 2020, 367 (6478), 610-611. 
Anthony, S. J.; Johnson, C. K.; Greig, D. J.; Kramer, S.; Che, X.; Wells, H.; Hicks, A. L.; Joly, D. O.; Wolfe, N. D.; Daszak, P.; Karesh, W.; Lipkin, W. I.; Morse, S. S.; Mazet, J. A. K.; Goldstein, T. Global Patterns in Coronavirus Diversity. Virus Evol. 2017, 3 (1), vex012. https://doi.org/10.1093/ve/vex012.

(9) Su, S.; Wong, G.; Shi, W.; Liu, J.; Lai, A. C. K.; Zhou, J.; Liu, W.; Bi, Y.; Gao, G. F. Epidemiology, Genetic Recombination, and Pathogenesis of Coronaviruses. Trends Microbiol. 2016, 24 (6), 490-502. https://doi.org/10.1016/j.tim.2016.03.003.

(10) Zhu, N.; Zhang, D.; Wang, W.; Li, X.; Yang, B.; Song, J.; Zhao, X.; Huang, B.; Shi, W.; Lu, R.; Niu, P.; Zhan, F.; Ma, X.; Wang, D.; Xu, W.; Wu, G.; Gao, G. F.; Tan, W. A Novel Coronavirus from Patients with Pneumonia in China, 2019. N. Engl. J. Med. 2020, $382 \quad$ (8), 727-733. https://doi.org/10.1056/NEJMoa2001017.

(11) Tang, B.; Bragazzi, N. L.; Li, Q.; Tang, S.; Xiao, Y.; Wu, J. An Updated Estimation of the Risk of Transmission of the Novel Coronavirus (2019-NCov). Infect. Dis. Model. 2020, 5, 248255. https://doi.org/10.1016/j.idm.2020.02.001

(12) Liu, C.; Zhou, Q.; Li, Y.; Garner, L. V.; Watkins, S. P.; Carter, L. J.; Smoot, J.; Gregg, A. C.; Daniels, A. D.; Jervey, S.; Albaiu, D. Research and Development on Therapeutic Agents and Vaccines for COVID-19 and Related Human Coronavirus Diseases. ACS Cent. Sci. 2020, 6 (3), 315-331. https://doi.org/10.1021/acscentsci.0c00272.

(13) Ghosh, A. K.; Brindisi, M.; Shahabi, D.; Chapman, M. E.; Mesecar, A. D. Drug Development and Medicinal Chemistry Efforts toward SARS-Coronavirus and Covid-19 Therapeutics. ChemMedChem 2020, $15 \quad$ (11), 907-932. https://doi.org/10.1002/cmdc.202000223.

(14) Elfiky, A. A. Anti-HCV, Nucleotide Inhibitors, Repurposing against COVID-19. Life Sci. 2020, 248 (February). https://doi.org/10.1016/j.lfs.2020.117477.

(15) Elfiky, A. A. Ribavirin, Remdesivir, Sofosbuvir, Galidesivir, and Tenofovir against SARS-CoV-2 RNA Dependent RNA Polymerase (RdRp): A Molecular Docking Study. Life Sci. 2020, 253 (March). https://doi.org/10.1016/j.lfs.2020.117592.

(16) Shah, B.; Modi, P.; Sagar, S. R. In Silico Studies on Therapeutic Agents for COVID-19: Drug Repurposing Approach. Life Sci. 2020, 252, 117652. https://doi.org/10.1016/j.lfs.2020.117652.

(17) Kumar, S.; Sharma, P. P.; Shankar, U.; Kumar, D.; Joshi, S. K.; Pena, L.; Durvasula, R.; Kumar, A.; Kempaiah, P.; Poonam; Rathi, B. Discovery of New Hydroxyethylamine Analogs against 3CL pro Protein Target of SARS-CoV-2: Molecular Docking, Molecular Dynamics Simulation, and StructureActivity Relationship Studies . J. Chem. Inf. Model. 2020. https://doi.org/10.1021/acs.jcim.0c00326.

(18) Asai, A.; Konno, M.; Ozaki, M.; Otsuka, C.; Vecchione, A.; Arai, T.; Kitagawa, T.; Ofusa, K.; Yabumoto, M.; Hirotsu, T.; Taniguchi, M.; Eguchi, H.; Doki, Y.; Ishii, H. COVID-19 Drug Discovery Using Intensive Approaches. Int. J. Mol. Sci. 2020, 21 (8). https://doi.org/10.3390/ijms21082839.

(19) Wang, J. Fast Identification of Possible Drug Treatment of Coronavirus Disease-19 (COVID-19) through Computational Drug Repurposing Study. J. Chem. Inf. Model. 2020, 60 (6), 3277-3286. https://doi.org/10.1021/acs.jcim.0c00179.

(20) Joshi, S.; Joshi, M.; Degani, M. S. Tackling SARS-CoV-2: Proposed Targets and Repurposed Drugs. Future Med. Chem. 2020, 12 (17), 1579-1601. https://doi.org/10.4155/fmc-20200147 .

(21) Kalamatianos, K. G. Drug Repurposing for Coronavirus (COVID-19): In Silico Screening of Known Drugs Against the SARS-CoV-2 Spike Protein Bound to Angiotensin Converting Enzyme $\quad 2 \quad$ (ACE2) (6M0J). https://doi.org/10.26434/chemrxiv.12857678.v2.

(22) Kalamatianos, K. G. Drug Repurposing for Coronavirus (COVID-19): In Silico Screening of Known Drugs Against the SARS-CoV-2 Spike Protein Bound to Angiotensin Converting $\begin{array}{llll}\text { Enzyme } & 2 & \text { (ACE2) }\end{array}$ https://doi.org/10.26434/chemrxiv.12857678.v1.

(23) Sadeghi, A.; Ali Asgari, A.; Norouzi, A.; Kheiri, Z.; Anushirvani, A.; Montazeri, M.; Hosamirudsai, H.; Afhami, S.; Akbarpour, E.; Aliannejad, R.; Radmard, A. R.; Davarpanah, A. H.; Levi, J.; Wentzel, H.; Qavi, A.; Garratt, A.; Simmons, B.;
Hill, A.; Merat, S. Sofosbuvir and Daclatasvir Compared with Standard of Care in the Treatment of Patients Admitted to Hospital with Moderate or Severe Coronavirus Infection (COVID-19): A Randomized Controlled Trial. J. Antimicrob. Chemother. 2020, $75 \quad$ (11), 3379-3385. https://doi.org/10.1093/jac/dkaa334.

(24) Lan, J.; Ge, J.; Yu, J.; Shan, S.; Zhou, H.; Fan, S.; Zhang, Q.; Shi, X.; Wang, Q.; Zhang, L.; Wang, X. Structure of the SARSCoV-2 Spike Receptor-Binding Domain Bound to the ACE2 Receptor. Nature 2020, $581 \quad$ (7807), 215-220. https://doi.org/10.1038/s41586-020-2180-5.

(25) Goodfellow, I. J.; Pouget-Abadie, J.; Mirza, M.; Xu, B.; WardeFarley, D.; Ozair, S.; Courville, A.; Bengio, Y. Generative Adversarial Nets. In Proceedings of the 27th International Conference on Neural Information Processing Systems - Volume 2; NIPS'14; MIT Press: Cambridge, MA, USA, 2014; pp 2672 2680.

(26) Zhu, J.-Y.; Zhang, R.; Pathak, D.; Darrell, T.; Efros, A. A.; Wang, O.; Shechtman, E. Toward Multimodal Image-to-Image Translation. In Proceedings of the 31st International Conference on Neural Information Processing Systems; NIPS'17; Curran Associates Inc.: Red Hook, NY, USA, 2017; pp 465-476.

(27) Skalic, M.; Jiménez, J.; Sabbadin, D.; De Fabritiis, G. ShapeBased Generative Modeling for de Novo Drug Design. J. Chem. Inf. Model. 2019, $59 \quad$ (3), 1205-1214. https://doi.org/10.1021/acs.jcim.8b00706.

(28) Jiménez, J.; Škalič, M.; Martínez-Rosell, G.; De Fabritiis, G. KDEEP: Protein-Ligand Absolute Binding Affinity Prediction via 3D-Convolutional Neural Networks. J. Chem. Inf. Model. 2018, $58 \quad$ (2), 287-296. https://doi.org/10.1021/acs.jcim.7b00650.

(29) Daina, A.; Michielin, O.; Zoete, V. SwissADME: A Free Web Tool to Evaluate Pharmacokinetics, Drug-Likeness and Medicinal Chemistry Friendliness of Small Molecules. Sci. Rep. 2017, 7 (March), 1-13. https://doi.org/10.1038/srep42717.

(30) Lipinski, C. A. Drug-like Properties and the Causes of Poor Solubility and Poor Permeability. J. Pharmacol. Toxicol. Methods 2000, 44 (1). https://doi.org/10.1016/S10568719(00)00107-6.

(31) Lipinski, C. A.; Lombardo, F.; Dominy, B. W.; Feeney, P. J. Experimental and Computational Approaches to Estimate Solubility and Permeability in Drug Discovery and Development Settings. Advanced Drug Delivery Reviews. 2012. https://doi.org/10.1016/j.addr.2012.09.019.

(32) Daina, A.; Zoete, V. A BOILED-Egg To Predict Gastrointestinal Absorption and Brain Penetration of Small Molecules. ChemMedChem 2016, 1117-1121. https://doi.org/10.1002/cmdc.201600182.

(33) Brandenburg, J. G.; Hochheim, M.; Bredow, T.; Grimme, S. Low-Cost Quantum Chemical Methods for Noncovalent Interactions. J. Phys. Chem. Lett. 2014, 5 (24), 4275-4284. https://doi.org/10.1021/jz5021313.

(34) Du, L.; He, Y.; Zhou, Y.; Liu, S.; Zheng, B.-J.; Jiang, S. The Spike Protein of SARS-CoV--a Target for Vaccine and Therapeutic Development. Nat. Rev. Microbiol. 2009, 7 (3), 226-236. https://doi.org/10.1038/nrmicro2090.

(35) Neese, F. The ORCA Program System. WIREs Comput. Mol. Sci. 2012, 2 (1), 73-78. https://doi.org/https://doi.org/10.1002/wcms.81.

(36) Neese, F. Orca 4.2.1. Wiley Interdiscip. Rev. Comput. Mol. Sci. 2012, 2, 73 .

(37) Auer, A. A.; Tran, V. A.; Sharma, B.; Stoychev, G. L.; Marx, D.; Neese, F. A Case Study of Density Functional Theory and Domain-Based Local Pair Natural Orbital Coupled Cluster for Vibrational Effects on EPR Hyperfine Coupling Constants: Vibrational Perturbation Theory versus $\mathrm{Ab}$ Initio Molecular Dynamics. Mol. Phys. 2020, 118 (19-20), 1-16. https://doi.org/10.1080/00268976.2020.1797916.

(38) Trott, O.; Olson, A. J. AutoDock Vina: Improving the Speed and Accuracy of Docking with a New Scoring Function, Efficient Optimization, and Multithreading. J. Comput. Chem. 2010, 31 (2), 455-461. https://doi.org/10.1002/jcc.21334.

(39) Ravindranath, P. A.; Forli, S.; Goodsell, D. S.; Olson, A. J.; Sanner, M. F. AutoDockFR: Advances in Protein-Ligand Docking with Explicitly Specified Binding Site Flexibility. PLoS Comput. Biol. 2015, 11 (12), e1004586. 

https://doi.org/10.1371/journal.pcbi.1000634.

(41) Morris, G. M.; Lim-Wilby, M. Molecular Docking. Methods Mol. Biol. 2008, 443, 365-382. https://doi.org/10.1007/978-159745-177-2_19.

(42) Hay, M.; Thomas, D. W.; Craighead, J. L.; Economides, C.; Rosenthal, J. Clinical Development Success Rates for Investigational Drugs. Nat. Biotechnol. 2014, 32 (1), 40-51. https://doi.org/10.1038/nbt.2786.

(43) Domingo, L. R.; Ríos-Gutiérrez, M.; Pérez, P. Applications of the Conceptual Density Functional Theory Indices to Organic Chemistry Reactivity. Molecules 2016, $21 \quad$ (6). https://doi.org/10.3390/molecules21060748.

(44) Wade, R. C.; Goodford, P. J. The Role of Hydrogen-Bonds in Drug Binding. Prog. Clin. Biol. Res. 1989, 289, 433-444.

(45) Sarwar, M. G.; Ajami, D.; Theodorakopoulos, G.; Petsalakis, I. D.; Rebek, J. J. Amplified Halogen Bonding in a Small Space. J. Am. Chem. Soc. 2013, 135 (37), 13672-13675. https://doi.org/10.1021/ja407815t.

(46) Lipkus, A. H. A Proof of the Triangle Inequality for the Tanimoto Distance. J. Math. Chem. 1999, 26 (1), 263-265. https://doi.org/10.1023/A:1019154432472.

(47) Chung, N. C.; Miasojedow, B.; Startek, M.; Gambin, A Jaccard/Tanimoto Similarity Test and Estimation Methods for Biological Presence-Absence Data. BMC Bioinformatics 2019, 20 (15), 644. https://doi.org/10.1186/s12859-019-3118-5.

(48) Rahman, S. A.; Bashton, M.; Holliday, G. L.; Schrader, R.; Thornton, J. M. Small Molecule Subgraph Detector (SMSD) $\begin{array}{llllll}\text { Toolkit. J. Cheminform. 2009, } 1 & \text { (1), } 12 .\end{array}$ https://doi.org/10.1186/1758-2946-1-12.

(49) Kubinyi, H. Similarity and Dissimilarity: A Medicinal Chemist's View. Perspect. Drug Discov. Des. 1998, 9 (0), 225252. https://doi.org/10.1023/A:1027221424359.

(50) LEVANDOWSKY, M.; WINTER, D. Distance between Sets. Nature 1971, 234 (5323), 34-35. https://doi.org/10.1038/234034a0.

(51) U.S. Patent 2007/0161691 A1, 2007.

(52) City, E.; Slusher, B. S.; Ferraris, D. V; Rojas, C.; Hin, N.; Duvall, B. (12) Patent Application Publication (10) Pub. No.: US 2015/0218156A1. 2015, 1 (19).

(53) Ci, U. S. Application. 2018, 1.

(54) Tian, X.; Liu, Y.; Zhu, J.; Yu, Z.; Han, J.; Wang, Y.; Han, W. Probing Inhibition Mechanisms of Adenosine Deaminase by Using Molecular Dynamics Simulations. PLoS One 2018, 13 (11), e0207234. https://doi.org/10.1371/journal.pone.0207234.

(55) Humphrey, W.; Dalke, A.; Schulten, K. VMD: Visual Molecular Dynamics. J. Mol. Graph. 1996, 14 (1), 33-38. https://doi.org/https://doi.org/10.1016/0263-7855(96)00018-5.

(56) Phillips, J. C.; Hardy, D. J.; Maia, J. D. C.; Stone, J. E.; Ribeiro, J. V; Bernardi, R. C.; Buch, R.; Fiorin, G.; Hénin, J.; Jiang, W.; McGreevy, R.; Melo, M. C. R.; Radak, B. K.; Skeel, R. D.; Singharoy, A.; Wang, Y.; Roux, B.; Aksimentiev, A.; LutheySchulten, Z.; Kalé, L. V; Schulten, K.; Chipot, C.; Tajkhorshid, E. Scalable Molecular Dynamics on CPU and GPU Architectures with NAMD. J. Chem. Phys. 2020,153 (4), 44130. https://doi.org/10.1063/5.0014475. 
APPENDIX A 


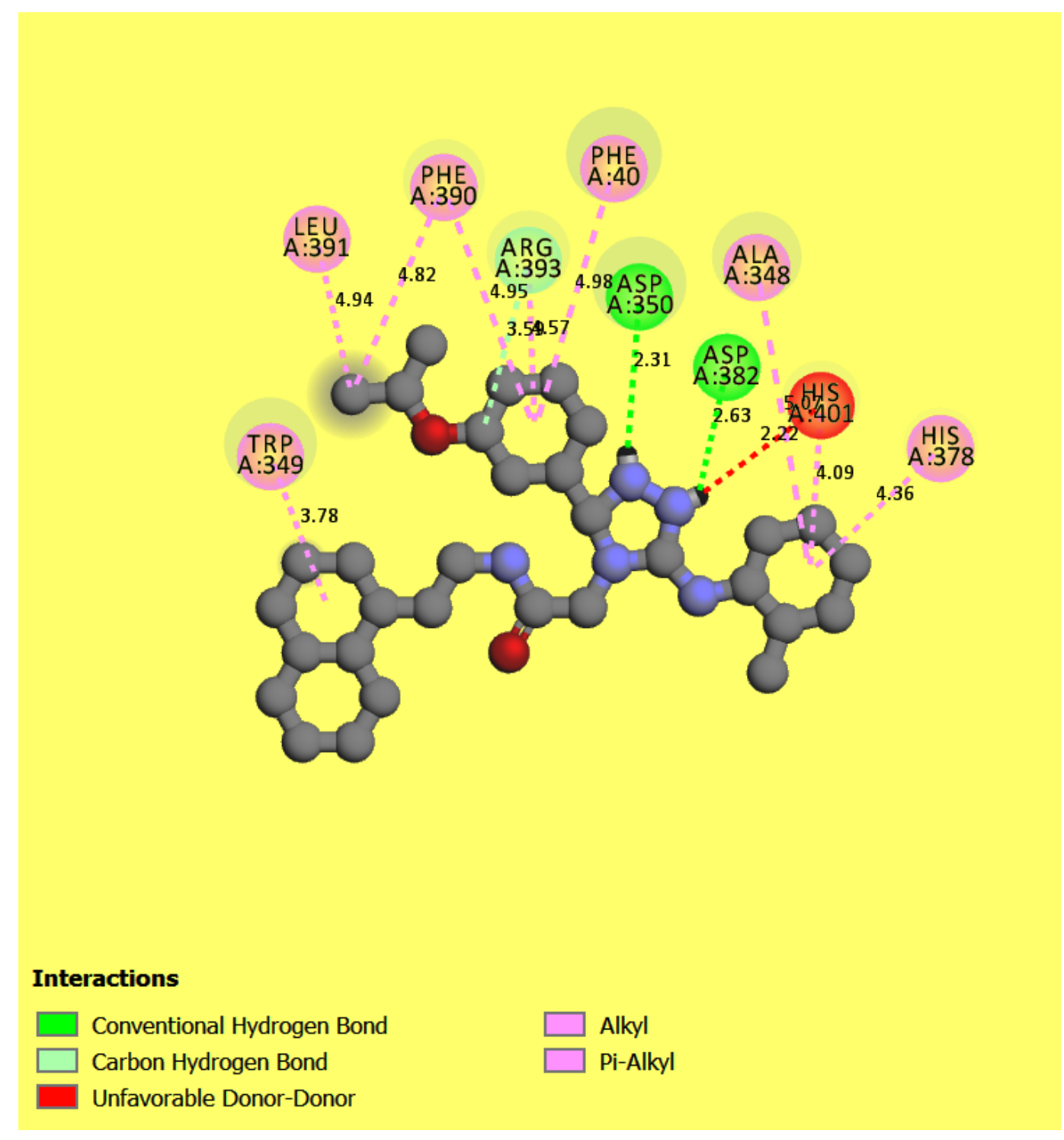

Figure 4 (expanded version): Docking interactions of compound 1 (Tables 1 \& 2) with 6M0J 


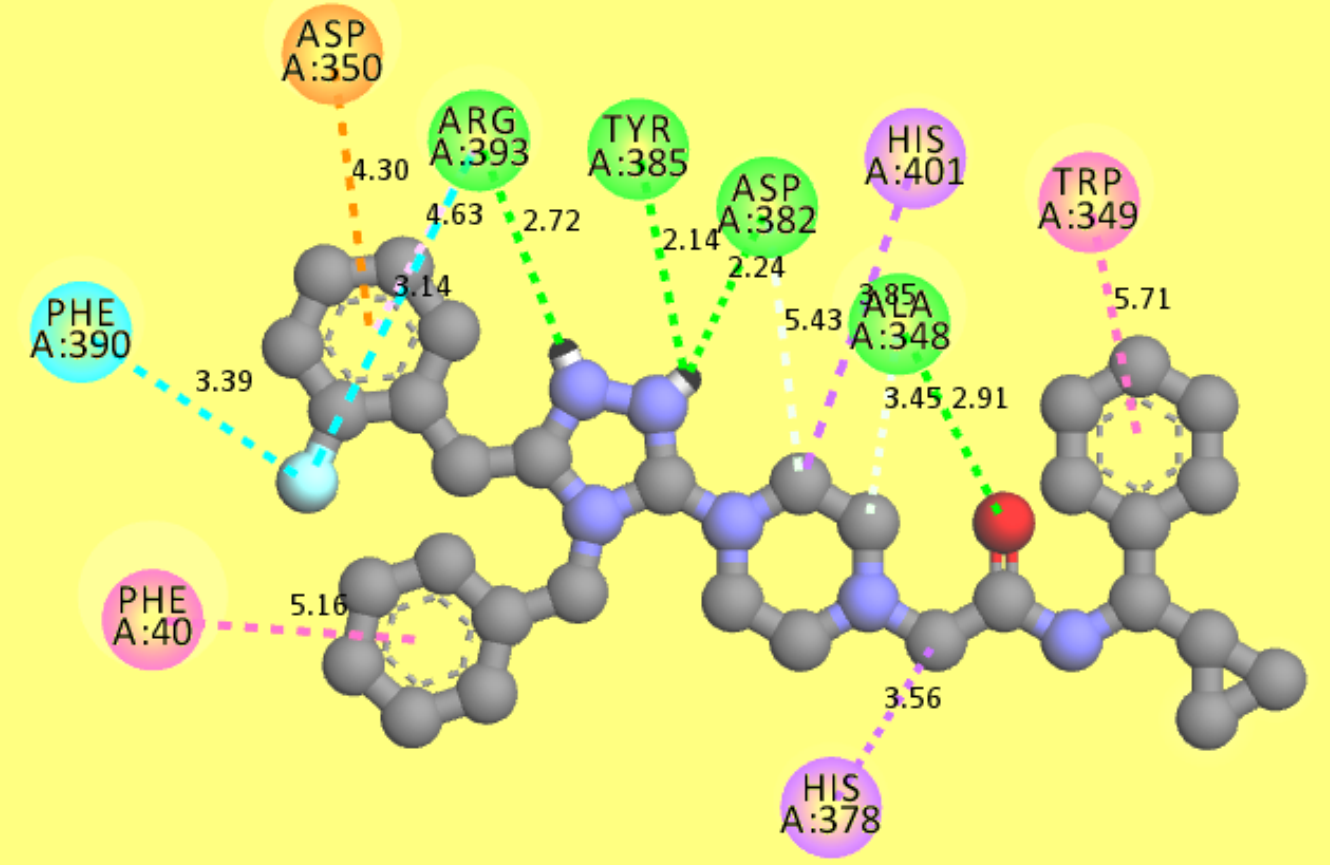

Interactions

Conventional Hydrogen Bond

Pi-Sigma

Carbon Hydrogen Bond

Pi-Pi T-shaped

Halogen (Fluorine)

Pi-Alkyl

\section{Pi-Anion}

Figure 5 (expanded version): Docking interactions of compound $\underline{8}$ (Tables $1 \& 2$ ) with $6 \mathrm{MOJ}$. 


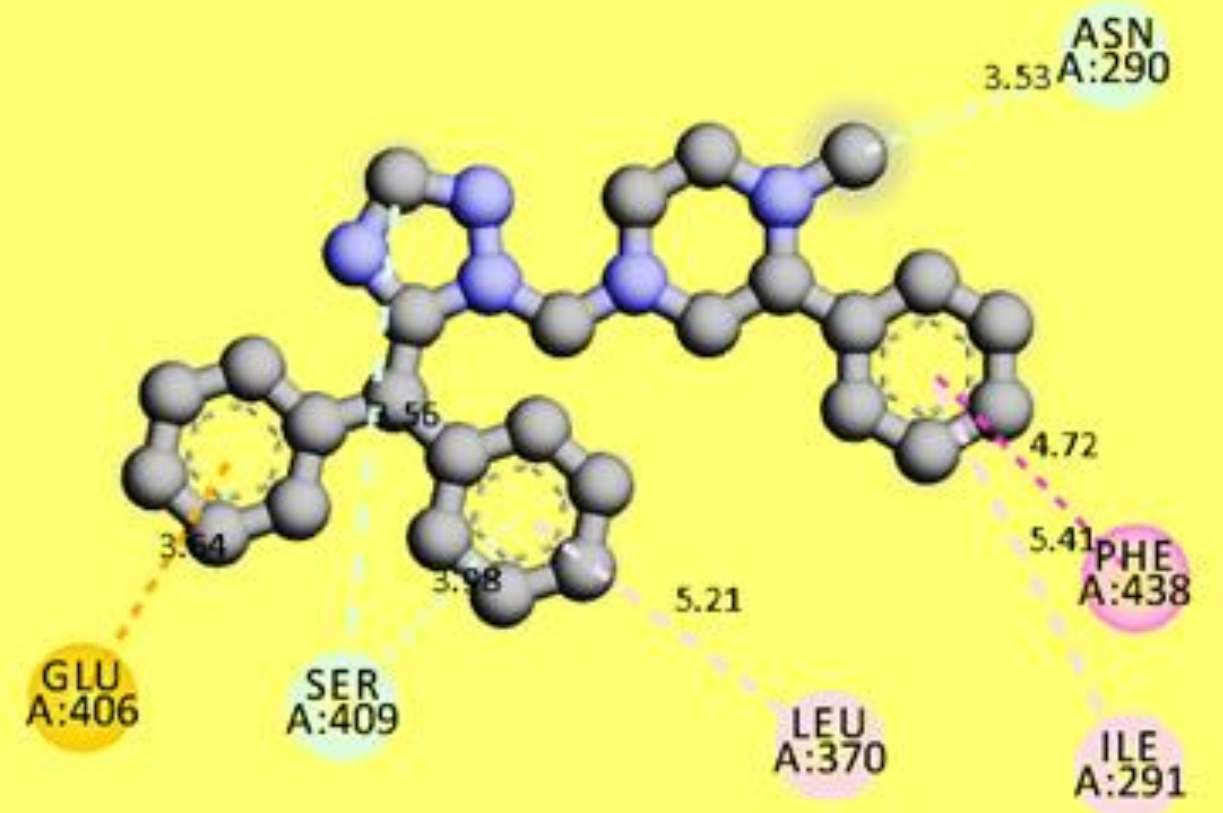

\section{Interactions}

$\square$ Carbon Hydrogen Bond

Pi-Anion

II Pi-Pi T-shaped

$\square$ Pi-Donor Hydrogen Bond

Pi-Alkyl

Figure 6 (expanded version): Docking interactions of compound $\underline{10}$ (Tables 1 \& 2) with $6 \mathrm{MOJ}$. 


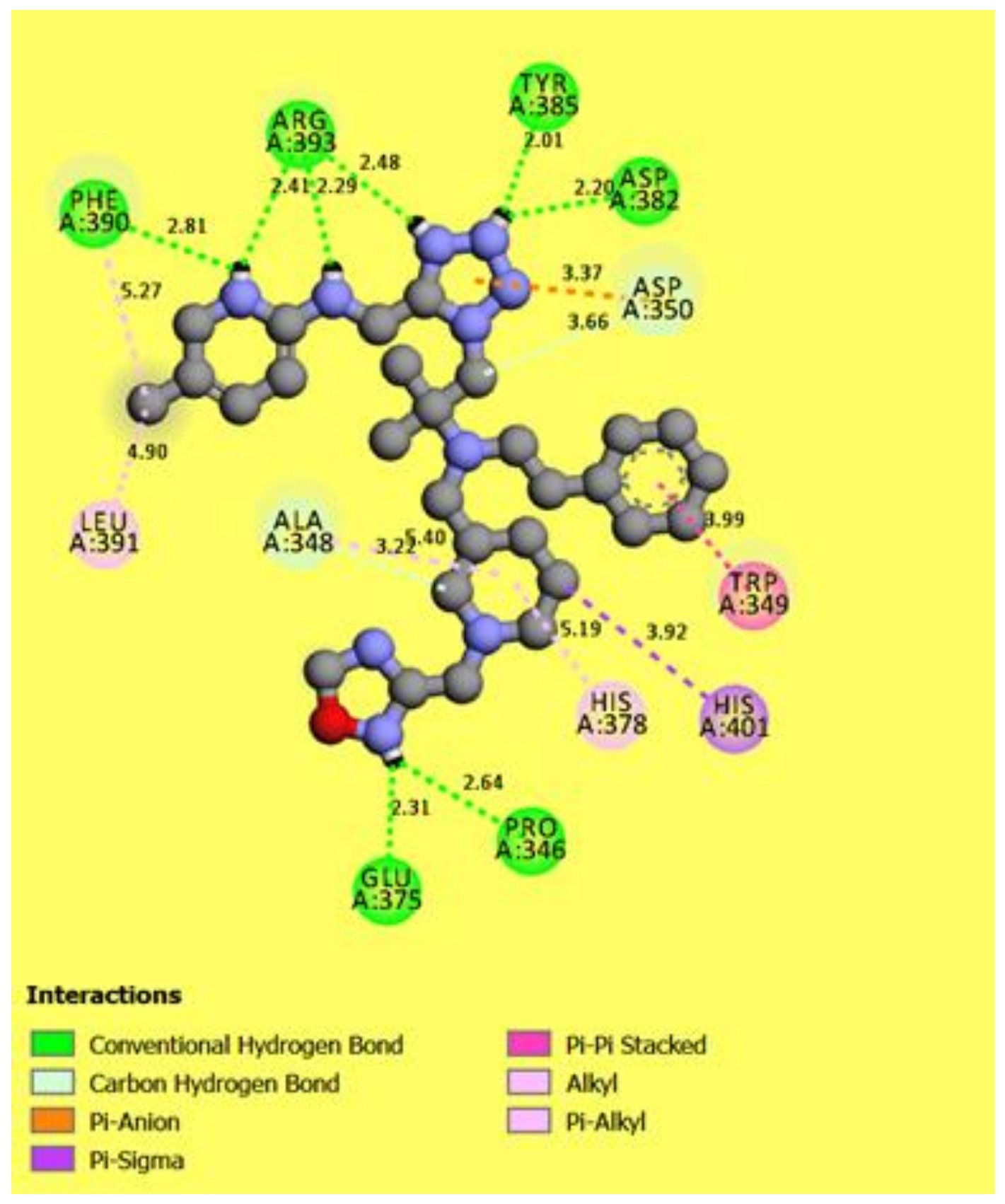

Figure 7 (expanded version). Docking interactions of compound 6 (Tables $1 \& 2$ ) with $6 \mathrm{MOJ}$. 
TABLE I: SARS-CoV-2 Spike protein (6M0J) - ligand (compound in Table 2) docking interactions and corresponding binding scores (kcal.mol-1).

\begin{tabular}{|c|c|c|c|c|c|c|c|c|c|}
\hline \# & Compound \# & $\begin{array}{c}\text { Docking } \\
\text { Score } \\
\left(\mathrm{kcal}^{\left.-\mathrm{mol}^{-1}\right)}\right.\end{array}$ & Distance (Å) & Category & Types & From & From Chemistry & To & To Chemistry \\
\hline \multirow[t]{14}{*}{1} & 1 & -9.7 & 2.62926 & H-Bond & Conventional H-Bond & :UNL1:H & H-Donor & A:ASP382:OD1 & H-Acceptor \\
\hline & & & 2.30533 & $\mathrm{H}$-Bond & Conventional H-Bond & :UNL1:H & H-Donor & A:ASP350:OD2 & H-Acceptor \\
\hline & & & 3.58984 & H-Bond & Carbon H-Bond & :UNL1:C & H-Donor & A:ARG393:0 & H-Acceptor \\
\hline & & & 4.9379 & Hydrophobic & Alkyl & :UNL1:C & Alkyl & A:LEU391 & Alkyl \\
\hline & & & 5.06948 & Hydrophobic & Alkyl & A:ALA348 & Alkyl & :UNL1 & Alkyl \\
\hline & & & 4.5719 & Hydrophobic & Alkyl & A:ARG393 & Alkyl & :UNL1 & Alkyl \\
\hline & & & 4.97574 & Hydrophobic & Pi-Alkyl & A:PHE40 & Pi-Orbitals & :UNL1 & Alkyl \\
\hline & & & 4.41719 & Hydrophobic & Pi-Alkyl & A:TRP349 & Pi-Orbitals & :UNL1 & Alkyl \\
\hline & & & 4.18809 & Hydrophobic & Pi-Alkyl & A:TRP349 & Pi-Orbitals & :UNL1 & Alkyl \\
\hline & & & 4.35845 & Hydrophobic & Pi-Alkyl & A:HIS378 & Pi-Orbitals & :UNL1 & Alkyl \\
\hline & & & 4.95142 & Hydrophobic & Pi-Alkyl & A:PHE390 & Pi-Orbitals & :UNL1 & Alkyl \\
\hline & & & 4.81831 & Hydrophobic & Pi-Alkyl & A:PHE390 & Pi-Orbitals & :UNL1:C & Alkyl \\
\hline & & & 4.09234 & Hydrophobic & Pi-Alkyl & A:HIS401 & Pi-Orbitals & :UNL1 & Alkyl \\
\hline & & & 2.01308 & H-Bond & Conventional H-Bond & A:MOLO:H & H-Donor & A:GLU208:O & H-Acceptor \\
\hline \multirow[t]{17}{*}{2} & 8 & -9.4 & 2.7163 & H-Bond & Conventional H-Bond & :UNL1:HN & H-Donor & A:ARG393:0 & H-Acceptor \\
\hline & & & 2.23943 & H-Bond & Conventional H-Bond & :UNL1:HN & H-Donor & A:ASP382:OD1 & H-Acceptor \\
\hline & & & 2.14154 & H-Bond & Conventional H-Bond & :UNL1:HN & H-Donor & A:TYR385:OH & H-Acceptor \\
\hline & & & 2.91278 & H-Bond & Conventional H-Bond & A:ALA348:N & H-Donor & :UNL1:O & H-Acceptor \\
\hline & & & 3.44558 & H-Bond & Carbon H-Bond & :UNL1:C & H-Donor & A:ALA348:0 & H-Acceptor \\
\hline & & & 3.26784 & H-Bond & Carbon H-Bond & :UNL1:C & H-Donor & A:ASP382:OD1 & H-Acceptor \\
\hline & & & 3.53411 & H-Bond & Carbon H-Bond & :UNL1:C & H-Donor & A:ASP382:OD2 & H-Acceptor \\
\hline & & & 3.39041 & Halogen & Halogen (Fluorine) & A:PHE390:O & Halogen Acceptor & :UNL1:F & Halogen \\
\hline & & & 3.14422 & Halogen & Halogen (Fluorine) & A:ARG393:0 & Halogen Acceptor & :UNL1:F & Halogen \\
\hline & & & 4.30012 & Electrostatic & Pi-Anion & A:ASP350:OD2 & Negative & :UNL1 & Pi-Orbitals \\
\hline & & & 3.84734 & Hydrophobic & Pi-Sigma & :UNL1:C & $\mathrm{C}-\mathrm{H}$ & A:HIS401 & Pi-Orbitals \\
\hline & & & 3.55507 & Hydrophobic & Pi-Sigma & :UNL1:C & $\mathrm{C}-\mathrm{H}$ & A:HIS378 & Pi-Orbitals \\
\hline & & & 5.93183 & Hydrophobic & Pi-Pi T-shaped & :UNL1 & Pi-Orbitals & :UNL1 & Pi-Orbitals \\
\hline & & & 5.15919 & Hydrophobic & Pi-Pi T-shaped & :UNL1 & Pi-Orbitals & A:PHE40 & Pi-Orbitals \\
\hline & & & 5.26407 & Hydrophobic & Pi-Pi T-shaped & :UNL1 & Pi-Orbitals & A:TRP349 & Pi-Orbitals \\
\hline & & & 4.97268 & Hydrophobic & Pi-Pi T-shaped & A:TRP349 & Pi-Orbitals & :UNL1 & Pi-Orbitals \\
\hline & & & 4.63497 & Hydrophobic & Pi-Alkyl & :UNL1 & Pi-Orbitals & A:ARG393 & Alkyl \\
\hline \multirow[t]{7}{*}{3} & 10 & -9.0 & 3.55862 & H-Bond & Carbon H-Bond & :UNL1:C & H-Donor & A:SER409:O & H-Acceptor \\
\hline & & & 3.53055 & H-Bond & Carbon H-Bond & :UNL1:C & H-Donor & A:ASN290:OD1 & H-Acceptor \\
\hline & & & 3.64458 & Electrostatic & Pi-Anion & A:GLU406:OE1 & Negative & :UNL1 & Pi-Orbitals \\
\hline & & & 3.97662 & H-Bond & Pi-Donor H-Bond & A:SER409:OG & H-Donor & :UNL1 & Pi-Orbitals \\
\hline & & & 4.71784 & Hydrophobic & Pi-Pi T-shaped & :UNL1 & Pi-Orbitals & A:PHE438 & Pi-Orbitals \\
\hline & & & 5.41022 & Hydrophobic & Pi-Alkyl & :UNL1 & Pi-Orbitals & A:ILE291 & Alkyl \\
\hline & & & 5.20509 & Hydrophobic & Pi-Alkyl & :UNL1 & Pi-Orbitals & A:LEU370 & Alkyl \\
\hline
\end{tabular}




\begin{tabular}{|c|c|c|c|c|c|c|c|c|c|}
\hline$\#$ & Compound \# & $\begin{array}{c}\text { Docking } \\
\text { Score } \\
\left({\left.\mathrm{kcal} . \mathrm{mol}^{-1}\right)}\right.\end{array}$ & Distance (Å) & Category & Types & From & From Chemistry & To & To Chemistry \\
\hline \multirow[t]{19}{*}{4} & 6 & -9.0 & 2.48035 & H-Bond & Conventional H-Bond & :UNL1:HN & H-Donor & A:ARG393:0 & H-Acceptor \\
\hline & & & 2.19986 & H-Bond & Conventional H-Bond & :UNL1:HN & H-Donor & A:ASP382:OD1 & H-Acceptor \\
\hline & & & 2.00752 & H-Bond & Conventional H-Bond & :UNL1:HN & H-Donor & A:TYR385:OH & H-Acceptor \\
\hline & & & 2.28969 & H-Bond & Conventional H-Bond & :UNL1:H & H-Donor & A:ARG393:0 & H-Acceptor \\
\hline & & & 2.80987 & H-Bond & Conventional H-Bond & :UNL1:HN & H-Donor & A:PHE390:O & H-Acceptor \\
\hline & & & 2.4064 & H-Bond & Conventional H-Bond & :UNL1:HN & H-Donor & A:ARG393:O & H-Acceptor \\
\hline & & & 2.63794 & H-Bond & Conventional H-Bond & :UNL1:HN & H-Donor & A:PRO346:O & H-Acceptor \\
\hline & & & 2.3132 & H-Bond & Conventional H-Bond & :UNL1:HN & H-Donor & A:GLU375:OE1 & H-Acceptor \\
\hline & & & 3.66465 & H-Bond & Carbon H-Bond & :UNL1:C & H-Donor & A:ASP350:0 & H-Acceptor \\
\hline & & & 3.22274 & H-Bond & Carbon H-Bond & :UNL1:C & H-Donor & A:ALA348:O & H-Acceptor \\
\hline & & & 3.36754 & Electrostatic & Pi-Anion & A:ASP350:OD2 & Negative & :UNL1 & Pi-Orbitals \\
\hline & & & 3.82779 & Hydrophobic & Pi-Sigma & :UNL1:C & $\mathrm{C}-\mathrm{H}$ & :UNL1 & Pi-Orbitals \\
\hline & & & 3.9235 & Hydrophobic & Pi-Sigma & :UNL1:C & $\mathrm{C}-\mathrm{H}$ & A:HIS401 & Pi-Orbitals \\
\hline & & & 4.10365 & Hydrophobic & Pi-Pi Stacked & :UNL1 & Pi-Orbitals & A:TRP349 & Pi-Orbitals \\
\hline & & & 5.00716 & Hydrophobic & Pi-Pi Stacked & A:TRP349 & Pi-Orbitals & :UNL1 & Pi-Orbitals \\
\hline & & & 4.89887 & Hydrophobic & Alkyl & :UNL1:C & Alkyl & A:LEU391 & Alkyl \\
\hline & & & 5.40014 & Hydrophobic & Alkyl & A:ALA348 & Alkyl & :UNL1 & Alkyl \\
\hline & & & 5.19273 & Hydrophobic & Pi-Alkyl & A:HIS378 & Pi-Orbitals & :UNL1 & Alkyl \\
\hline & & & 5.26567 & Hydrophobic & Pi-Alkyl & A:PHE390 & Pi-Orbitals & :UNL1:C & Alkyl \\
\hline \multirow[t]{6}{*}{5} & 7 & -8.8 & 3.72677 & H-Bond & Conventional H-Bond & :UNL1:S & H-Donor & A:TYR385:OH & H-Acceptor \\
\hline & & & 3.60879 & H-Bond & Conventional H-Bond & :UNL1:S & H-Donor & A:ASN394:OD1 & H-Acceptor \\
\hline & & & 3.39852 & H-Bond & Carbon H-Bond & :UNL1:C & H-Donor & A:ASP382:OD1 & H-Acceptor \\
\hline & & & 3.39517 & H-Bond & Carbon H-Bond & :UNL1:C & H-Donor & A:ASP382:OD2 & H-Acceptor \\
\hline & & & 4.11334 & Hydrophobic & Pi-Pi Stacked & :UNL1 & Pi-Orbitals & A:PHE40 & Pi-Orbitals \\
\hline & & & 4.85585 & Hydrophobic & Pi-Pi T-shaped & :UNL1 & Pi-Orbitals & A:PHE40 & Pi-Orbitals \\
\hline \multirow[t]{15}{*}{6} & 4 & -8.7 & 2.51326 & H-Bond & Conventional H-Bond & :UNL1:HN & H-Donor & A:GLU208:0 & H-Acceptor \\
\hline & & & 2.75715 & H-Bond & Conventional H-Bond & :UNL1:H & H-Donor & A:GLY205:O & H-Acceptor \\
\hline & & & 3.14176 & H-Bond & Carbon H-Bond & :UNL1:C & H-Donor & A:GLY205:O & H-Acceptor \\
\hline & & & 3.89575 & Electrostatic & Pi-Anion & A:GLU208:OE1 & Negative & :UNL1 & Pi-Orbitals \\
\hline & & & 3.66257 & H-Bond & Pi-Donor H-Bond & A:GLN98:NE2 & H-Donor & :UNL1 & Pi-Orbitals \\
\hline & & & 4.1355 & H-Bond & Pi-Donor H-Bond & A:GLN102:NE2 & H-Donor & :UNL1 & Pi-Orbitals \\
\hline & & & 5.59457 & Hydrophobic & Pi-Pi T-shaped & :UNL1 & Pi-Orbitals & A:TYR202 & Pi-Orbitals \\
\hline & & & 4.18999 & Hydrophobic & Amide-Pi Stacked & A:GLY205:C,O;ASP206:N & Amide & :UNL1 & Pi-Orbitals \\
\hline & & & 5.03736 & Hydrophobic & Alkyl & :UNL1:C & Alkyl & A:LEU95 & Alkyl \\
\hline & & & 4.11736 & Hydrophobic & Alkyl & :UNL1:C & Alkyl & A:ALA99 & Alkyl \\
\hline & & & 4.58504 & Hydrophobic & Alkyl & :UNL1:CL & Alkyl & A:LEU95 & Alkyl \\
\hline & & & 3.89614 & Hydrophobic & Alkyl & :UNL1:CL & Alkyl & A:VAL209 & Alkyl \\
\hline & & & 5.11088 & Hydrophobic & Alkyl & A:LYS562 & Alkyl & :UNL1 & Alkyl \\
\hline & & & 5.46948 & Hydrophobic & Pi-Alkyl & :UNL1 & Pi-Orbitals & A:LEU95 & Alkyl \\
\hline & & & 5.48879 & Hydrophobic & Pi-Alkyl & :UNL1 & Pi-Orbitals & A:LYS562 & Alkyl \\
\hline
\end{tabular}




\begin{tabular}{|c|c|c|c|c|c|c|c|c|c|}
\hline$\#$ & Compound \# & $\begin{array}{c}\text { Docking } \\
\text { Score } \\
\left(\mathrm{kcal}^{\left.-\mathrm{mol}^{-1}\right)}\right.\end{array}$ & Distance (Å) & Category & Types & From & From Chemistry & To & To Chemistry \\
\hline \multirow[t]{8}{*}{7} & 5 & -8.6 & 2.42488 & H-Bond & Conventional H-Bond & :UNL1:HN & H-Donor & A:GLN98:O & H-Acceptor \\
\hline & & & 2.45729 & H-Bond & Conventional H-Bond & :UNL1:HN & H-Donor & A:TYR196:OH & H-Acceptor \\
\hline & & & 3.5969 & H-Bond & Carbon H-Bond & :UNL1:C & H-Donor & A:LYS562:O & H-Acceptor \\
\hline & & & 3.64841 & H-Bond & Carbon H-Bond & UNL1:C & H-Donor & A:GLU564:O & H-Acceptor \\
\hline & & & 3.45573 & H-Bond & Carbon H-Bond & :UNL1:C & H-Donor & A:ALA396:0 & H-Acceptor \\
\hline & & & 3.79732 & Hydrophobic & Pi-Sigma & A:ALA99:CB & $\mathrm{C}-\mathrm{H}$ & :UNL1 & Pi-Orbitals \\
\hline & & & 3.74991 & Hydrophobic & Pi-Pi Stacked & :UNL1 & Pi-Orbitals & :UNL1 & Pi-Orbitals \\
\hline & & & 4.72549 & Hydrophobic & Amide-Pi Stacked & A:GLN101:C,O;GLN102:N & Amide & :UNL1 & Pi-Orbitals \\
\hline \multirow[t]{8}{*}{8} & 3 & -8.3 & 2.62991 & H-Bond & Conventional H-Bond & :UNL1:HN & H-Donor & A:TYR202:0 & H-Acceptor \\
\hline & & & 2.96802 & H-Bond & Conventional H-Bond & :UNL1:HN & H-Donor & A:ASP206:OD1 & H-Acceptor \\
\hline & & & 3.2265 & H-Bond & Carbon H-Bond & :UNL1:C & H-Donor & A:ASP206:OD1 & H-Acceptor \\
\hline & & & 3.67828 & H-Bond & Carbon H-Bond & :UNL1:C & H-Donor & A:TRP203:0 & H-Acceptor \\
\hline & & & 4.41485 & Electrostatic & Pi-Cation & A:LYS562:NZ & Positive & :UNL1 & Pi-Orbitals \\
\hline & & & 3.78984 & Hydrophobic & Pi-Pi Stacked & :UNL1 & Pi-Orbitals & :UNL1 & Pi-Orbitals \\
\hline & & & 4.98016 & Hydrophobic & Alkyl & :UNL1:CL & Alkyl & A:LEU95 & Alkyl \\
\hline & & & 5.10147 & Hydrophobic & Pi-Alkyl & :UNL1 & Pi-Orbitals & A:ALA99 & Alkyl \\
\hline
\end{tabular}

